EXPLORING INDIGENOUS-NEWCOMER RELATIONS IN THE CITY OF TORONTO:

CHANGING DEMOGRAPHICS, RECONCILIATION, AND

THE POTENTIAL OF CITY PLANNING

by

Niko Casuncad, BA, University of Calgary, 2018

\author{
A Major Research Paper \\ presented to Ryerson University \\ in partial fulfillment of the requirements for the degree of \\ Master of Planning \\ in the Program of \\ Urban Development
}

Toronto, Ontario, Canada, 2020

(C) Niko Casuncad 2020 


\section{$\underline{\text { AUTHOR'S DECLARATION FOR ELECTRONIC SUBMISSION OF A THESIS }}$}

I hereby declare that I am the sole author of this major research project. This is a true copy of the MRP, including any required final revisions, as accepted by my examiners.

I authorize Ryerson University to lend this paper to other institutions or individuals for the purpose of scholarly research.

I further authorize Ryerson University to reproduce this MRP by photocopying or by other means, in total or in part, at the request of other institutions or individuals for the purpose of scholarly research.

I understand that my MRP may be electronically available to the public.

Niko Casuncad 


\title{
EXPLORING INDIGENOUS-NEWCOMER RELATIONS IN THE CITY OF TORONTO: CHANGING DEMOGRAPHICS, RECONCILIATION, AND THE CAPACITY OF CITY PLANNING
}

(C) Niko Casuncad 2020

\author{
Master of Planning \\ in \\ Urban Development \\ Ryerson University
}

\begin{abstract}
Toronto's urban Indigenous and newcomer populations are rapidly increasing. As a result, the City is facing a new demographic reality that will change how the municipal government implements its plans, designs, and programs. Indigenous and newcomer groups often have similar lived experiences of marginalization and discrimination as equity-seeking groups and can work together towards a more just city. This Major Research Paper (MRP) lays at the intersection of this new demographic reality, the Truth and Reconciliation Commission of Canada's (TRC) Calls to Action, and how planning might play an important role in supporting Indigenous-newcomer relations. A qualitative approach was used to explore the City's current level of engagement with the TRC's Calls to Action and the City's Statement of Commitment to Aboriginal Communities in Toronto. Data collection included a document scan of City plans, engagement strategies, and divisional strategies; an initiative scan of events, reports to action, and council motions; and semi-structured interviews with City staff in the following divisions: City Planning; the Indigenous Affairs Office; the Newcomer Office; Economic Development and Culture; and Parks, Forestry, and Recreation.
\end{abstract}

Key words: Reconciliation, Immigrant, Newcomer, Indigenous, City, Planning, Demographics, Toronto 


\section{ACKNOWLEDGEMENTS}

Firstly, I would like to thank my supervisor, Dr. Magdalena Ugarte, for showing great enthusiasm, passion, and support of my MRP. If not for Dr. Ugarte I do not believe that this MRP would have come to fruition. Dr. Ugarte has supported me by challenging me to think about my research questions from different perspectives within equity, diversity, and social justice in planning, which helped me grow academically and personally in the program. She has been a great mentor. I would also like to extend my gratitude to my second reader Dr. Anna Triandafyllidou. I am thankful for the support that the Canada's Excellence Research Chair in Migration and Integration has given. I have learned so much from Dr. Triandafyllidou's leadership at Ryerson University. I would like to thank my interviewee participants, especially the Indigenous Affairs office and the Newcomer Office at the City of Toronto for showing great enthusiasm to participate in my MRP.

A special thanks goes to Ira and Ashley. They have supported me through all my ups and all my downs in any possible way they could. I would also like to thank all my friends and fellow Urban Development cohort who provided me encouragement and reassurance when I needed it. I am greatly indebted to you all. I also would like to thank faculty and administrative leadership at Ryerson University's School of Urban and Regional Planning for ensuring students are supported, especially during the COVID-19 in Toronto.

Finally, I would like to thank my Mom and family for always believing in me, for always being proud of me, and for always showing me unconditional love. 


\section{DEDICATION}

For my Mom who without her continuous support throughout the years I am not sure that I would be where I am today. Thank you for believing in me and working so hard to care for your family in the Philippines and Canada. 


\section{Table of Contents}

ABSTRACT

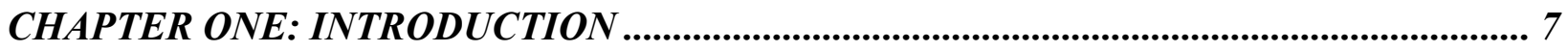

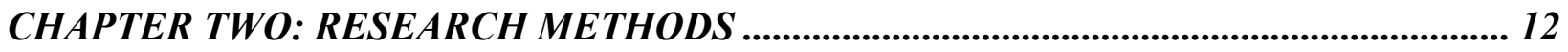

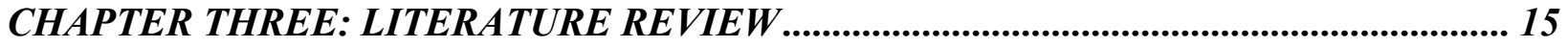

Indigenous History \& Immigration in Canada ............................................................................................ 16

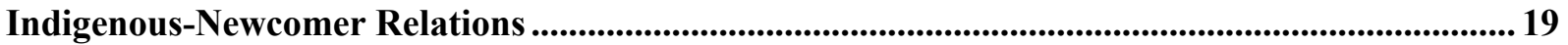

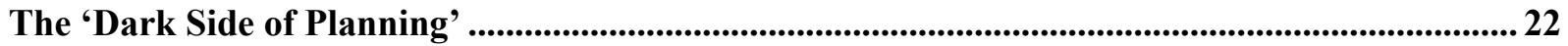

Reconciliation and Planning in Canada................................................................................................... 24

Role of Municipalities in Managing Differences and................................................................................ 25

Supporting Co-Existence, Diversity and Reconciliation ............................................................................. 25

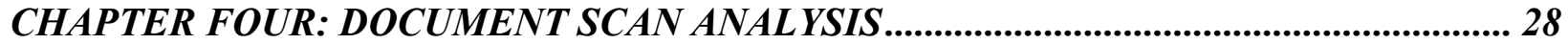

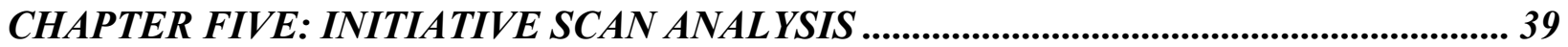

CHAPTER SIX: SEMI-STRUCTURED INTERVIEW ANAL YSIS ................................... 44

TRUTH \& RECONCILIATION COMMISSION CALLS TO ACTION \& RECONCILIATION

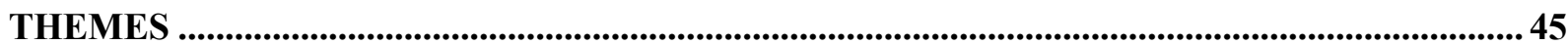

Theme 1: "Nothing About Us Without Us": Importance of the TRC and Indigenous-Led Leadership \&

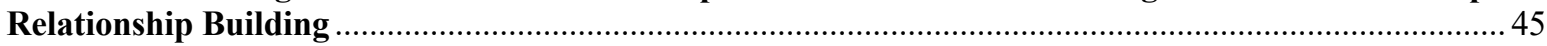

Theme 2: Going Beyond "Over-Consultation”: Meaningful Engagement and Process ........................... 48

Theme 3: Learning and Competency Training: "People get it in a way that people haven't got ten years

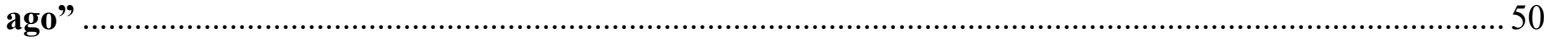

INDIGENOUS-NEWCOMER RELATIONS THEMES..........................................................51

Theme 4: "We haven't responded as we should be": More work still needs to be done .........................51

Theme 5: A Demographic Change \& Immigration Settlement Challenges ................................................. 52

Theme 6: Education First: Reducing Misinformation \& Negative Stereotypes .......................................54

Theme 7: Celebration \& Recognition Through Arts \& Culture ............................................................ 55

Theme 8: The Importance of Implementing City-Wide Indigenous Place-making Efforts ..................... 56

CHAPTER SEVEN: CONCLUSION: PAST, PRESENT, AND FUTURE OF INDIGENOUSNEWCOMER RELATIONS ................................................................................................5 59

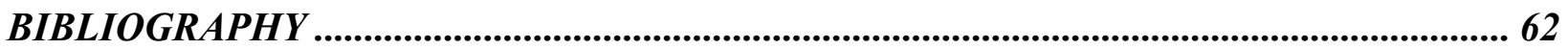

Appendix A: Document Scan (Strategies and Plans) .........................................................................66

Appendix B: Initiative Scan (Action Plans, Events, and Working Groups) ...................................... 69

Appendix C: Thematic Coding Keywords................................................................................................... 72

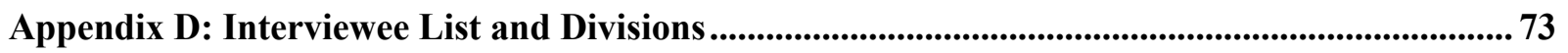

Appendix E: Interview Guide with Questions ...............................................................................74 


\section{CHAPTER ONE: INTRODUCTION}

\section{Demographic Change}

Toronto's urban Indigenous ${ }^{1}$ and immigrant ${ }^{2}$ populations are rapidly increasing (O'Donnell \& LaPointe, 2019; Statistics Canada 2017). In 2016, Toronto was home to $17.5 \%$ of all recent immigrants to the country and it currently has Canada's fourth largest urban Indigenous population (Statistics Canada, 2017). As a result, the City of Toronto is facing a new demographic reality that will change how municipal governments plan, design, and program the city. Many large and mid-sized cities across Canada such as Winnipeg and Vancouver are also experiencing the same demographic trend of increasing immigration and a growing young Indigenous population (Gyepi-Garbrah et al., 2019). At the same time, Canada is facing pressure from Indigenous communities and groups to acknowledge Indigenous people's rights, sovereignty, and self-determination (Porter \& Barry, 2016). As a result of this demographic shift, in 2031, Toronto will become a so-called majority-minority, a jurisdiction in which one or more racial and/or ethnic minorities make up a majority of the local population (Statistics Canada, 2017). Given the rapid growth of immigration to Canada it is important to address how ethnocultural groups live with each other, especially how they interact with and learn about the diverse First Nations, Metis, and Inuit peoples of Canada.

\section{Truth and Reconciliation Commission of Canada Calls to Action and Reconciliation}

In 2015, the Truth and Reconciliation Commission of Canada (TRC) ${ }^{3}$, which was mandated to inform all Canadians about Indian Residential Schools, released their report and 94 Calls to Action urging all levels of government to work together to change policies and programs in a concerted effort to repair the harm caused by residential schools and move forward with reconciliation. Reconciliation ${ }^{4}$ as defined by the TRC is the collective effort from all peoples to revitalize the relationship between Aboriginal

\footnotetext{
${ }^{1}$ Aboriginal identity refers to those persons who reported to the 2016 census as belonging to at least one Aboriginal group; that is, North American Indian, Métis or Inuit, and/or those who reported being a Treaty Indian or a Registered Indian, as defined by the Indian Act of Canada, and/or those who reported they were members of an Indian band or First Nation (Statistics Canada, 2017).

${ }^{2}$ Immigrant to refers "to a person who is, or who has ever been, a landed immigrant or permanent resident. Such a person has been granted the right to live in Canada permanently by immigration authorities. Immigrants who have obtained Canadian citizenship by naturalization are included in this group" (Statistics Canada, 2017).

${ }^{3}$ Truth and Reconciliation Commission (TRC): The TRC is a component of the Indian Residential Schools Settlement Agreement that was approved in 2006 and began to be implemented in the following year. The TRC was a five-year mandate and was supported by a TRC Secretariat, which is a federal government department. The TRC prepared a historical record on the policies and operations of the schools and produced the Calls to Action report that includes recommendations to the Government of Canada concerning the IRS system and its legacy. The TRC hosted seven national events in different regions across Canada to promote awareness and public education about the IRS system and its impacts. The National Centre of Truth and Reconciliation research centre at University of Manitoba was established by the end of the TRC mandate, providing permanent resource that all Canadians can access (TRC, 2015).

${ }^{4}$ Reconciliation: The cumulative impact of residential schools is a legacy of unresolved trauma passed from generation to generation and has had a profound effect on the relationship between Aboriginal peoples and other Canadians. Reconciliation is the collective effort of all non-Indigenous and Indigenous peoples to build a new relationship (TRC, 2015).
} 
peoples and Canadian society, a goal that will take multiple generations to achieve (TRC, 2015). The TRC and its report have sparked a national discussion on redressing the colonial legacy and impacts of the Indian Residential Schools on Indigenous peoples.

Despite this discourse, there are still unresolved tensions and ongoing discussions amongst Canadians, political leaders, and Indigenous communities across the country. As I conducted research for this MRP in January 2020, Canadians stood peacefully in solidarity across the country with the Wet'suwet'en people as they opposed a 670-kilometre pipeline led by Coastal GasLink ${ }^{5}$, putting pressure on the Prime Minister to uphold his commitment to diversity and tackle the deep-rooted inequities facing Indigenous peoples. With many debates and discussions occurring, Indigenous leaders and communities are saying "Reconciliation is Dead" in the current context of the Wet'suwet'en pipeline conflict in British Columbia. As nation-wide discussions are happening around Indigenous sovereignty and reconciliation, at the municipal level, actions are being taken by City staff and council members regarding their commitments to specific areas of the TRC report and Calls to Action.

\section{City of Toronto Statement of Commitment to Aboriginal Communities}

In 2010, the City of Toronto adopted the Statement of Commitment to the Aboriginal Communities of Toronto - Towards a Framework for Urban Aboriginal Relations in Toronto (Toronto, n.d.). The Statement of Commitment declared the Toronto City Council's commitment to the principle of Aboriginal self-determination and to establishing mechanisms for full civic participation by all residents in the social, economic, cultural and political life of the City (City of Toronto, 2015). The Aboriginal Affairs Committee of Toronto ${ }^{6}$ oversees the implementation of the Statement of Commitment. The Aboriginal Affairs Committee prioritized three Commitments from the Statement for implementation. The three Commitments relate to education of the Toronto Public Service on Aboriginal culture and history, increasing Aboriginal representation on City agencies and corporations, and increasing the number of Aboriginal employees at all levels in the City of Toronto. The Equity, Diversity and Human Rights (EDHR) Division, in partnership with Human Resources and other City divisions, is responsible for implementing the three Commitments.

\footnotetext{
${ }^{5}$ Wet'suwet'en Conflict: At the centre of the Wet'suwet'en conflict is a multi-billion-dollar natural gas project and an assertion by Wet'suwet'en hereditary chiefs that no pipelines can be built through their traditional territory without their consent. The \$6billion, 670-kilometre Coastal GasLink pipeline has received approval from the province, and 20 First Nations band councils have signed agreements in support of the project, including five of the six band councils in the Wet'suwet'en nation (CBC Indigenous News, 2020).

${ }^{6}$ Aboriginal Affairs Committee of Toronto: The Aboriginal Affairs Committee of Toronto is an advisory body to the Mayor and City Council. The Committee's duties include using their knowledge and expertise to provide advice to the City Council through the standing committees of Council and to act as a liaison with external bodies on barriers to participation in public life and to the achievement of the social, cultural and economic well-being of the city's residents (City of Toronto, n.d.).
} 
The first Commitment focuses on creating training opportunities for the Toronto Public Service to learn about the history of Indigenous communities and its current day impacts from Aboriginal Elders and other Aboriginal partners. The second commitment is to work with Aboriginal communities to improve public awareness of Aboriginal life in Toronto. The third commitment is to work with Aboriginal partners to explore ways to strengthen the capacity of Aboriginal organizations and associations to plan, lead, and deliver initiatives for local Aboriginal communities. The fourth commitment is to implement employment practices that ensure that opportunities for employment are accessible to Aboriginal people and increase the number of Aboriginal employees at all occupational levels. The fifth commitment is to work formally and informally with all orders of government and other municipalities, institutions and community organizations to continue exploring promising practices and opportunities for collaboration on Aboriginal initiatives and to promote the interests of Aboriginal people in Toronto, as defined by Aboriginal communities. Lastly, the sixth commitment is to develop an action plan in partnership with Aboriginal communities to ensure there is an accountability process in place to measure the success of the Statement of Commitment.

In addition to the adoption of the Statement in 2015, the City identified eight Calls to Action from the TRC's report as priorities for implementation. They include the following priority areas: health (call to action \#23), reconciliation (call to action \#43), professional development and training for public servants (call to action \#57), museums and archives (call to action \#68), a national centre for Truth and Reconciliation (call to action \#77), commemoration (call to action \#82), sports and reconciliation (call to action \#88), and newcomers to Canada (call to action \#94). I am interested in calls to action $43^{7}, 57,{ }^{8}$ and $93^{9}$, which call on municipal governments to take action on reconciliation and ensure newcomers understand the diverse history of Indigenous people. The City of Toronto has taken steps to ensure that at the municipal level there is initiative and action taken by staff and divisions for their commitments to Aboriginal communities.

\footnotetext{
${ }^{7}$ Call to Action 43: Governments and the United Nations Declaration on the Rights of Indigenous People. "We call upon federal, provincial, territorial, and municipal governments to fully adopt and implement the United Nations Declaration on the Rights of Indigenous Peoples as the framework for reconciliation" (TRC, 2015).

${ }^{8}$ Call to Action 57: Professional Development and Training for Public Servants. "We call upon federal, provincial, territorial, and municipal governments to provide education to public servants on the history of Aboriginal peoples, including the history and legacy of residential schools, the United Nations Declaration on the Rights of Indigenous Peoples, Treaties and Aboriginal rights, Indigenous law, and Aboriginal-Crown relations. This will require skills-based training in intercultural competency, conflict resolution, human rights, and anti-racism" (TRC, 2015).

${ }^{9}$ Call to Action 93 Newcomers to Canada: "We call upon the federal government, in collaboration with the national Aboriginal organizations, to revise the information kit for newcomers to Canada and its citizenship test to reflect a more inclusive history of the diverse Aboriginal peoples of Canada, including information about the Treaties and the history of residential schools" (TRC, 2015).
} 


\section{Planning Profession and Reconciliation}

In the contexts just described, at the planning profession level, the Canadian Institute of Planners and the Ontario Professional Institute of Planners have released a draft policy statement on planning practice and reconciliation (CIP, 2019) and a report on Indigenous perspectives in planning (OPPI, 2019). These documents call for the profession to respond to the findings of the TRC, which are framing the reconciliation conversation nationally. The CIP and OPPI suggest that the profession must acknowledge the role of historic planning practices in the mistreatment of Indigenous peoples in order to build and strengthen relationships based on respect and understanding. The CIP calls on planners to advocate for and work to co-create meaningful planning processes among Indigenous communities and other levels of government. Both the CIP and OPPI state that planners play unique public roles that can nurture reconciliation on a shared journey with Indigenous peoples, planners, and communities (CIP, 2019; OPPI, 2019). The OPPI has attempted to outline some opportunities and challenges on how the planning profession can improve its understanding of the impacts of colonial laws and policies on Indigenous peoples. This role includes understanding the implications and expectations arising from the TRC's report and Calls to Action and the United Nations Declaration on the Rights of Indigenous Peoples (UNDRIP) ${ }^{10}$ for their areas of practice and integrating them into their professional practice.

\section{Research Focus/Question}

Over the years, First Nations, urban Aboriginal groups and immigrant organizations have acknowledged that there is limited interaction among them (Wong and Fong, 2011). Given the demographic changes Canada is experiencing, coexistence is necessary to address inevitable conflicts such as hate crimes, segregation, avoidance, apprehension or rivalry that may arise in multicultural and diverse cities (Sandercock 2009; Guidikova and Wood, 2012). Urban planning plays an important role in establishing coexistence and facilitating cross-cultural dialogue and understanding in our increasingly diverse cities (Porter, 2013). In addition to avoiding conflict across differences, managing conflict is also important because Indigenous peoples are the owners and stewards of these lands, it is every person's obligation to uphold treaties in Canada. "We are all treaty people" is a phrase commonly used to describe that all people living in Canada are treaty people ${ }^{11}$ with their own set of rights and responsibilities.

\footnotetext{
${ }^{10}$ The United Nations Declaration on the Rights of Indigenous Peoples is a document that describes both individual and collective rights of Indigenous peoples around the world. It offers guidance on cooperative relationships with Indigenous peoples to states, the United Nations, and other international organizations based on the principles of equality, partnership, good faith and mutual respect. The declaration was adopted by resolution of the United Nations General Assembly on September 13, 2007 (TRC, 2015). In May 2016, Canada's Minister of Indigenous and Northern Affairs announced that Canada is now a full supporter, without qualification, of the declaration (Government of Canada, 2016).

${ }^{11}$ Treaty People: To learn more read Tara Williamson's 2012 article "We are all Treaty People".
} 
Treaties $^{12}$ are a foundational part of Canadian society because they have been made or are being made with the original inhabitants and are living documents between Indigenous and non-Indigenous peoples (Mishenene \& Dugale, n.d.). The urban planning profession and practice play an important role in managing the natural environment, climate change, and water and land management. As such, all people living on these lands, including newcomers to Canadian cities, have an obligation to uphold these treaties. Non-Indigenous peoples must acknowledge that Indigenous peoples are at the forefront of protecting the natural environment, climate control, water quality and rights on their land (Williamson, 2012).

This Major Research Paper (MRP) lies at the intersection of this changing demographic in Canadian cities, national discussions about reconciliation, and the potential of City Planning to foster and support Indigenous-newcomer relations to further advance reconciliation between non-Indigenous and Indigenous people. In particular, I seek to investigate how the City of Toronto has or has not made progress in their commitments to Aboriginal communities in Toronto as expressed in the Statement of Commitment and their commitment to the TRC Calls to Action. This MRP will explore how municipal planning has the potential to play an important role in creating spaces for Indigenous and newcomer groups to collaborate to create a just and equitable city, and to further advance reconciliation.

Specifically, the research goal is to understand whether or not the City of Toronto is committing to or working towards planning with a focus on advancing reconciliation and supporting Indigenous-immigrant relations. To explore these issues, the overarching research question guiding my inquiry is:

How are municipal planners and staff in the City of Toronto engaging (or not engaging) with the City's commitment to the TRC's calls to action regarding Indigenous-immigrant relations in their practice?

My research objectives include:

1. To investigate what the TRC's Calls to Action mean for the City of Toronto's goals and initiatives.

2. To explore the current level of engagement of municipal staff with the TRC's calls to action regarding Indigenous-newcomer relations.

\footnotetext{
${ }^{12}$ Treaties: Treaties are agreements made between the Government of Canada, Indigenous groups and often provinces and territories that define ongoing rights and obligations on all sides. These agreements set out continuing treaty rights and benefits for each group. Treaty rights and Aboriginal rights (commonly referred to as Indigenous rights) are recognized and affirmed in Section 35 of the Constitution Act, 1982 and are also a key part of the United Nations Declaration on the Rights of Indigenous Peoples which the Government of Canada has committed to adopt. Treaties with Indigenous peoples include both historic treaties with First Nations and modern treaties (also called comprehensive land claim agreements) with Indigenous groups (Government of Canada, n.d). Ontario is covered by 46 treaties and other agreements, such as land purchased by the Crown signed between 1781 and 1930 (Smith, 2016).
} 
3. To identify barriers, challenges and opportunities municipal staff face when engaging and working on initiatives with Indigenous and newcomer groups in their projects.

This topic is timely because of the current demographic changes Toronto is experiencing, the ongoing conversations of reconciliation and specifically how municipal planning is playing (or not) a vital role in advancing reconciliation between non-Indigenous and Indigenous peoples. Understanding that Canadian cities are facing new demographic changes from increasing immigration and a growing young Indigenous population, it is important to investigate how the City of Toronto is working towards building stronger relationships between newcomers and Indigenous peoples. It has been many years since the City's Statement of Commitment was developed and the TRC's report and Calls to Action were released, and it is important to investigate whether or not municipal planning and staff are responding to further advancing reconciliation.

\section{CHAPTER TWO: RESEARCH METHODS}

Examining how municipal planners and the City of Toronto are engaging with the TRCs calls to action towards reconciliation requires a qualitative approach. The data collection methods in this MRP included a document scan, an initiative scan, and semi-structured interviews.

The document scan of engagement strategies, policy and legislation documents, divisional strategies, and urban planning and design guidelines was conducted to explore if the City was taking policy direction to guide action and implementation for advancing reconciliation and strengthening Indigenous-newcomer relations. The document scan identified key themes and explored how the City is setting their policy direction, or not, in relation to the City Statement of Commitment and the TRC Calls to Action.

Another data collection tool was an initiative scan of implementation and action items found in City of Toronto action plans, events, and committees. The initiative scan explored how the selected divisions interpreted policies into actionable projects and initiatives related to advancing reconciliation and Indigenous-newcomer relations for City staff and Toronto communities and residents. The main difference between the document scan and the initiative scan is that the document scan indicated if there was a broader policy direction and the initiative scan analyzed if there are actionable items in place or if they have been conducted before. For analytical purposes, the various documents and actions examined during the document and initiative scan were categorized based on whether they focused on reconciliation and/or on Indigenous-newcomer relations.

To further substantiate findings from both the document and initiative scan, semi-structured interviews were conducted with selected City of Toronto staff in identified divisions including the 
Newcomer Office; the Indigenous Affairs Office; City Planning, Economic Development and Culture; and Parks Forestry and Recreation, as I elaborate on below. The documents, initiatives, and potential interviewees were selectively chosen based on publicly available information from the City's website. Additionally, through snowballing sampling the Newcomer Office was added to the data collection process at the suggestion of the Indigenous Affairs Office.

The time-frame of this MRP involves documents and initiatives released after the Statement of Commitment, which was adopted by the City Council in 2010. As I will discuss below, the initiative and document scan helped identify how or if the TRC's calls to action regarding Indigenous-immigrant relations are addressed by the City of Toronto at the level of policy visions and goals, and through specific city-led initiatives. The semi-structured interviews shed light on how the TRC's Calls to Action are reflected in City of Toronto's visions, goals, or actions and have helped substantiate research findings from the document and initiative scan. As I discuss below, the analysis process involved selective coding to identify important concepts and themes, and axial coding to identify links between different concepts and themes.

\section{Divisions of Focus}

As of December 2019, there are over 40 operating divisions and over 35,000 staff working for the City of Toronto (City of Toronto, 2019). For the purpose of this MRP, I selected five divisions/offices to focus on (See Appendix D for City divisions). These divisions were selected because their policy documents and their action-oriented initiatives closely relate to advancing reconciliation and have the potential to support Indigenous-newcomer relations.

The City Planning Division helps guide and build Toronto's future by managing the growth and physical form of the city - how it looks, feels, and moves, and the opportunities it provides to its residents in terms of jobs and services (City of Toronto, 2015). City Planning policies and plans such as the Official Plan, Secondary Plans, Design Guidelines, and Heritage Conservation Districts \& Studies guide development and city-building initiatives. Municipal planning policies are guided by the Ontario Provincial Policy Statement, which sets out policies for the government's land use vision for how the city settles land, the built environment, and resources (City of Toronto, 2015). The Parks, Forestry \& Recreation Division is responsible for areas such as community development, parks, horticulture and forestry programs as well as park and open space planning and environmental initiatives (City of Toronto, n.d). The Economic Development \& Culture department strives to make Toronto a place where business and culture thrive. The division's objective is to advance Toronto's prosperity, opportunities and liveability by fostering employment and investment opportunities, encouraging Toronto's cultural vibrancy through more and enhanced cultural experiences, and engaging partners in the planning and 
development of the City's economic and cultural resources. This division is guided by the Economic Development and Culture Divisional Strategy (City of Toronto, n.d).

Within the Social Development, Administration, and Finance department are the Toronto Newcomer Office (TNO) and the Indigenous Affairs Office (IAO). The TNO was established to provide strategic leadership on newcomer and immigration-related issues in the City. Among other activities, the TNO convenes key stakeholders to address newcomer issues and facilitates the implementation of the Toronto Newcomer Strategy (City of Toronto, n.d). The IAO is focused on supporting City divisions in their work with First Nations, Inuit and Métis peoples and all urban Indigenous communities. The Office strives to strengthen the City's relationship with Indigenous communities and advance reconciliation (City of Toronto, n.d.). While the City remains committed to embedding the responsibility for Indigenous priorities across City divisions, the IAO provides focused and coordinated leadership on Indigenous affairs and works with Toronto's Aboriginal Affairs Committee. In 2015, City Council in consultation with the Aboriginal Affairs Committee identified eight Calls to Action from the TRC's report as priorities for implementation (City of Toronto, n.d). Some Calls to Action are mirrored in the Statement of Commitment such as reconciliation, professional development and training for public servants, and lastly, newcomers to Canada (City of Toronto, n.d). As such, these selected divisions are relevant because their departmental or office policies and initiatives are related to advancing reconciliation and/or Indigenous-newcomer relations.

\section{Document \& Initiative Scan}

The document scan involved the selective coding of seven selected documents (See Appendix A) including divisional strategies, the Official Plan, and engagement strategies in order to identify any action or responses to the Statement of Commitment or the TRC's Calls to Action. These documents were chosen because they identified the vision and goals for key City departments to guide more specific actions and areas for intervention. Through selective coding, I systematically looked for keywords (See Appendix C) to identify a strategic focus or visioning that indicates that advancing reconciliation and/or Indigenousnewcomer relations is considered in the document's overarching purpose. The strategy and visioning documents are important for identifying key issues or topics that City staff and elected officials are paying attention to. As such, they can shed light on the broader City policy direction of advancing reconciliation and/or strengthening and supporting Indigenous-newcomer relations.

The initiative scan looked at six specific initiatives (See Appendix B) and the implementation of those specific actions or initiatives that focused on advancing reconciliation or working towards supporting and facilitating Indigenous-newcomer relations. Included in the initiative scan are projects/actions that were selectively drawn based on publicly available information from the City's 
website of the selected divisions chosen for the scope of this MRP. The purpose of the initiative scan was to identify whether identified City divisions are taking leadership on Indigenous-immigrant relations or the TRC Calls to Action through specific actions carried out by any working groups/committees, as well as through consultation, events, or divisional projects.

\section{Semi-Structured Interviews with City of Toronto Staff}

Lastly, the semi-structured interviews helped provide deeper context and understanding of how City and staff are taking action or not in advancing reconciliation and supporting Indigenous-newcomer relations. The interviewees were guided by a set of questions regarding Indigenous-immigrant relations and reconciliation in their professional life/everyday practice (See Appendix E for the interview guide). The purpose of conducting these expert interviews with identified City of Toronto staff was to further examine whether or not staff were taking action, identifying any initiatives and actions undertaken by staff, identifying any challenges or barriers they encounter in their practice, and lastly, how staff can support and facilitate Indigenous-immigrant relations in various divisions. Each City division and department is led by strategic visioning and goals that define how staff interact with community members, other staff, and the City Council. The work these divisions carry out can shed light on how the municipal planning process of visioning and strategizing translates into the actual implementation of Indigenousimmigrant initiatives to inform better planning in Toronto. Hearing first-hand from City staff was important because it allowed the collection of professional and expert-based qualitative data that would not be accessible by just completing a document and initiative scan. Interviewing also provided opportunities to understand the rationale for how the City of Toronto is engaging or not with the TRC calls to action, providing more in-depth information on the complexity of municipal policy and initiatives.

\section{CHAPTER THREE: LITERATURE REVIEW}

Canadian cities have been instrumental in consolidating and perpetuating settler colonialism. The acknowledgement of this complicity has led to discussions about governments taking action to advance reconciliation in this country (Porter, 2013). At the same time, municipalities are tasked with ensuring successful integration and settlement of newcomers in cities. This literature review will dive deeper into how municipalities are responding to the demographic shift introduced in previous sections and to discussions about reconciliation. Understanding the history of Indigenous people and immigration and how differences are managed in cities will be elaborated on. I will discuss the links between Indigenous history and immigration in Canada in more detail, elaborating on the history of settler colonization, the history of immigration in Canada, and the TRC. Then, I will discuss the importance of strengthening 
Indigenous-newcomer relations in cities and how the demographic shift is important for planners to pay attention to. The third topic of the literature review will discuss the 'dark side' of planning, and how the practice and profession has historically disadvantaged Indigenous and immigrant communities. The fourth topic of the literature review will focus on how the planning profession and practices are responding to working towards reconciliation. The last topic will tie all the literature together by addressing how municipalities play an important role in managing difference, co-existence, and reconciliation in urban settings. To further explore Indigenous-newcomer relations in Toronto, it is important to understand the roots of colonial history and how planning has helped dispossess Indigenous peoples of their land and their cultures. This literature review grounds the research work in the history of Indigenous people on this land and the historical demographic trends that have resulted in the diversity of Canada today.

\section{Indigenous History \& Immigration in Canada}

\section{Settler Colonialism in Canada}

Indigenous Peoples have been present on the lands we know as Canada for more than 15,000 years (OPPI, 2019). The Doctrine of Discovery, which indicated that only Christians had right of title to land, dictated the actions of European settlers across what is now North America and dispossessed Indigenous Peoples from their traditional territories (OPPI, 2019). The First Nations peoples were impacted by the contact with the first European arrivals and were further dislocated and dispossessed by European settlers who claimed land for farming, urban development, and resource extraction (Sandercock and Brock, 2009) Indigenous peoples have been dispossessed of not only their land, but also of the political, cultural, and socio-economic responsibility to govern their lands according to customary ancestral law (Porter and Barry, 2017). The state of Canada supported the assimilation of Indigenous peoples through the residential school system, the reserve system, and through federal, provincial, and territorial legislation and policy. As described by Cox (2017), settler colonialism is an ongoing system of power that perpetuates the genocide and repression of Indigenous peoples and cultures. Therefore, Canada is an example of settler colonialism that is still perpetuated today with federal legislation and policy.

For over 100 years, Aboriginal children were removed from their families and sent to institutions called residential schools. The government-funded, church-run schools located across Canada were established with the purpose of eliminating parental involvement in the spiritual, cultural and intellectual development of Aboriginal children (TRC, 2015). During this chapter in Canadian history, more than 150,000 First Nations, Métis, and Inuit children were forced to attend these schools some of which were hundreds of miles from their home. The cumulative impact of residential schools is a legacy of 
unresolved trauma passed from generation to generation and has had a profound effect on the relationship between Aboriginal peoples and other Canadians.

Legislation by the Canadian government during and after Confederation, and up to the present day have further served to dispossess Indigenous Peoples from their traditional territories, cultures and traditions (e.g. The Indian Act - 1876). The Indian Act is a federal law that governs matters related to Indian status, bands, and reserves. Throughout history, it has been paternalistic, as it authorizes the Canadian federal government to regulate and administer in the affairs and day-to-day lives of registered Indians and reserve communities, and it still retains its original form (Hanson, 2009). An Indian Reserve is a tract of land set aside under the Indian Act and treaty agreements for the use of that land under an Indian Band. Those Bands have the right to live on reserve lands and have administrative and political structures in place (Hanson, 2009).

The reserve system had and still has implications for aspects of Aboriginal life on reserves. The reserve system disrupted social networks and long-established kinship systems that determined roles for people who could hunt, fish, and gather (Hanson, 2009). Another impact on reserves was the Crown's responsibility for the construction of housing on reserves. These houses were designed with the Western nuclear family unit in mind and were not culturally appropriate for the diverse groups of Indigenous people (Hanson, 2009). The housing system on reserves across the country have becomer symbolic of the dominant power system of the federal government as a result of colonial policies (McCartney, 2016). McCartney et al (2018) further explain that housing evaluation systems have played a critical role in the ongoing subjugation of First Nations peoples and their culture through their role in supporting ongoing state intervention in housing systems.

After centuries of dispossession of land and impacts on the social, economic, and physical aspects of Indigenous peoples through legislation, the reserve system, and the Indian residential school system, there has been a shift to a nation-wide discussion between non-Indigenous and Indigenous peoples on moving forward from the injustices committed to discussions around reconciliation (Bauder $\&$ Reesor, 2019). This MRP seeks to contribute to these efforts.

\section{Immigration and Diversity in Canada}

Canada is built on immigration and the composition of the foreign-born population has changed considerably in the past 150 years, with censuses revealing a shift in the places of birth of Canada's foreign-born population (Statistics Canada, 2016). In the past, immigrants to Canada mainly came from European countries such as the United Kingdom and Germany. Starting in the 1960s, when major amendments were made to Canada's immigration legislation and regulations, the number of immigrants from Asia and other regions of the world started to grow. Poverty, human insecurity, and conflict also 
contributed as important push factors to the massive movement of refugees and migrants from different parts of the world to Canada (Statistics Canada, 2016). Each wave of immigrants has contributed, and continues to contribute, to the ethnic, linguistic and religious diversity of Canada's population (Statistics Canada, 2016). Also, for the first time since Confederation, China and India have surpassed the United Kingdom as the country of birth most frequently reported by foreign-born people (Statistics Canada, 2016). As a result of these trends, immigration has changed a great deal since Confederation, becoming the main driver of population growth in Canada (Statistics Canada, 2016).

\section{Truth and Reconciliation Commission of Canada}

The TRC was a component of the Indian Residential Schools Settlement Agreement, which was released in 2006, while implementation of the agreement began in 2007. As mentioned earlier, the TRC was mandated by the TRC secretariat as part of the Indian Residential Settlement Agreement for five years to focus on truth and reconciliation and inform Canadians about what happened in Indian Residential Schools (IRS). The Commission documented what survivors, families, and communities experienced with the IRS through statement gathering, research, and public education (TRC, 2015). In 2015, the TRC released their final report with their key findings and produced 94 calls to action. The TRC report describes the acts against Indigenous peoples on the land as a form of cultural genocide because of the destruction of the structures and practices that allow a group to continue as a group. Since December 2015, the TRC offices have been closed because the TRC reached the end of the five year mandate, and the work of the TRC has been transferred to the National Centre for Truth and Reconciliation at the University of Manitoba in Winnipeg, Manitoba. According to the TRC (2015), reconciliation is

\footnotetext{
About establishing and maintaining a mutually respectful relationship between Aboriginal and nonAboriginal peoples in this country... In order for that to happen, there has to be awareness of the past, an acknowledgement of the harm that has been inflicted, atonement for the causes, and action to change behaviour. (p.7)
}

The TRC was created out of the importance of shedding light on a part of history that was not understood by many. The TRC acknowledges that the IRS are a part of Canada's shared history. According to the TRC, Canada's relationship with Aboriginal people has suffered as a result of the IRS system. For Indigenous and non-Indigenous governments and people, healing and repairing that relationship requires education, awareness, and an increased understanding of the legacy and impacts still being felt by Indigenous people.

Because of the demographic trends described earlier, the work of the TRC includes newcomers to the country. This poses some challenges for immigration settlement and integration in Canadian cities 
because of the different languages spoken, communication styles, and decision-making processes. Reconciliation with immigration and diversity is an opportunity to ensure that newcomers from diverse ethnocultural backgrounds can understand the history and current impacts of settler colonialism on the many diverse Indigenous groups across the country.

\section{Indigenous-Newcomer Relations}

Today, there are ongoing discussions amongst political leaders, Indigenous leaders, and stakeholders across the country about reconciliation, Indigenous sovereignty, and land/resource management. However, at the same time, there is an increasing focus on the importance of further exploring Indigenous-newcomer relations (Bauder, 2019). Canada also faces a new challenge of ensuring that newcomers are aware of and educated on Indigenous peoples, cultures, and histories to ensure that the process of reconciliation is ongoing between non-Indigenous and Indigenous people. Newcomers often come to Canada with little or highly distorted knowledge of Indigenous people. However, De Costa and Clarke (2011) argue that the nature of Canadian social diversity and change has not been attended to in discussions on reconciliation. An assumption of an undifferentiated category of "non-Aboriginal Canadians" is no more of a useful way to proceed than is the persistent generalization of Aboriginal people in a range of cultural discourse and policy discussions.

Bauder (2019) revealed a gap that typically characterizes public debate related to Indigenous peoples in Canada and immigration and settlement. On the one side, we see Canada as a nation of immigrants that provides newcomers with a new home, no matter where they come from. On the other side, we see Indigenous peoples' claim to belong to the land because they have always been here. According to the author, we tend to separate these two narratives, choosing to discuss either immigration or reconciliation, but not how the two are related or how they can be reconciled. However, the links between colonization and immigration are clear and longstanding. First, European colonizers and settlers displaced Aboriginal peoples, appropriated their land, and denied them a political voice. This type of settlement through appropriation set the stage for the establishment of a new community built on largescale immigration that excluded Aboriginal peoples (Bauder 2011). In this way, a clear material link exists between immigration and Aboriginal experiences (Bauder 2011).

This clear link has the potential to further strengthen social and cultural bonds between Aboriginal peoples and newcomers which can be increased by their mutual recognition of common histories of colonialism in countries of origin and in Canada and by the socioeconomic challenges and racism encountered in Canadian cities (Gyepi-Garbrah et al. 2014). In fact, equity-seeking groups such as immigrants or Aboriginal people experience discrimination, racism, and are treated differently and are often disengaged or discouraged by the planning process (Gyepi-Garbrah et al., 2019). The changing 
demographic shift is important for planners to understand our changing populations in cities. This is also important to create space for collaboration between Indigenous and newcomer groups, reduce negative stereotypes, reduce racism and discrimination, and contribute meaningfully to society. Despite this fact, this gap between Indigenous and newcomers needs to be bridged with open dialogue and policy changes.

An important step towards reconciliation is that the settlement of newcomers begins with learning about this land and who it belongs to, while acknowledging the histories of settlement, genocide, displacement, and treaties (Reesor and Bauder, 2019). Similarly, Mathur et al., (2011) understand that reconciliation through cultural diversity is critical for newcomers to Canada to understand the history and relationship that Aboriginal people have had with the Crown, as it is different from other Canadians. Indigenous peoples and immigrant newcomers are embedded economically, culturally and politically in the urban fabric of modern settler states (Gyepi-Garbrah et al. 2014). However, it is also important to note that according to demographic trends, the majority of immigrants to Canada come from Asia including the Middle East, which a large number of diverse ethnocultural groups. This complicates the notion of settler colonialism and the white settlers who originally settled on the land we now call Canada. According to Phung (2011), assimilated people of colour can produce similar settler colonial narratives in order to belong in the dominant majority society. If there is not a proper system or program in place for newcomers who are people of colour and settle in Canada but do not know the history of the many diverse Indigenous peoples across the country, it may result in settler colonialism further dominating and repressing Indigenous people (Phung, 2011). As a result, both immigrant newcomers and Indigenous peoples can work together towards common ground with the collective work of rebuilding relationships and trust. In order for the country to move forward, ensuring that newcomers are included in this process is vital.

This MRP starts from the assumption that the planning process has the potential to catalyze meaningful cross-cultural learning about the legacies of colonialism, and that planners can improve community relations (Porter \& Barry 2016). However, even though Indigenous and immigration matters are closely connected there is a lack of attention given to Indigenous-newcomer relations on a nationwide scale. For instance, in the context of Toronto, no known research has been done on Indigenousnewcomer relations. However, studies have been completed on Indigenous-newcomer related topics in immigration settlement and community organizations in other cities.

An example of this is the Dialogues Project of the City of Vancouver (Wong \& Fong 2011), which was an intercultural learning and relationship-building project between Indigenous and Immigrant communities and addresses the gap identified by Bauder. Through hosting Dialogue Circles, in-depth interviews, surveys and participatory research, cultural exchanges, celebratory events, and youth and Elder engagement, the Dialogues Project involved hundreds of participants and created a legacy of 
understanding between Canada's original inhabitants and newcomers to Canada in Vancouver (Wong \& Fong 2011). According to Yu (2011),

The Dialogues Project was meant to engage in a sharing of our pasts - who we are and where we are from-but also to create a shared understanding about who we aspire to be in the future (Yu, 2011) Dialogues Project for me is an important part of a collective, collaborative project for those sets of people whose stories have often been silenced or ignored, so that they could speak and hear each other's stories. We hoped that each of us in listening would be able to know ourselves and each other a bit better, and to generate a dialogue that created a mutual understanding of our differences as well as what we shared in common (p. 306).

Along similar lines, Ghorayshi (2010) discusses the changing ethno-racial composition of Winnipeg's inner city due to immigration and attendant modes of social exclusion, how newcomers feel excluded from and distanced from Canadian society and the tensions between newcomers and the historical minority-Aboriginal people, who are disproportionately located in the inner city. In light of these realities Ghorayshi (2010) explains how a large number of government and non-governmental organizations that respond to the needs of immigrants and refugees are underfunded, which may be a concern as governments relegate their responsibilities to community-based organizations that struggle with funding issues. This is a particularly important issue and the cross-collaboration municipalities rely on will be further discussed in the research analysis section.

Madriaga-Vignudo (2009) argued that refugees' attitudes portray an overall negative evaluation of Aboriginals; however, Aboriginals appeared to have a mixed perception of refugees because of their minimal knowledge and relationships with refugees in inner-city Winnipeg. Gyepi-Garbrah et al. (2014) explored the importance of the role of community organizations (for example, Aboriginal self-governing urban organizations and immigrant newcomer settlement and support organizations) in creating spaces of interaction where new intercultural dimensions of the social, economic, political and material spatiality of the city can be produced. Examples from Gyepi-Garbrah et al. (2014) include how the growth of Aboriginal community-based organizations such as Ka Ni Kanichihk in Winnipeg worked to promote dialogue and intercultural understanding between Aboriginals and newcomers by creating initiatives such as a central market space that brought the two groups together. Therefore, cities are important spaces and places of encounter for all different groups in society.

The increasing Indigenous and immigrant newcomer population in Canadian cities poses challenges for municipalities that aim to build relationships and understanding between the two groups. The clear link between Indigenous' and immigrant newcomers' lived experiences provides an opportunity for municipalities and city planning. At the same time, there is increasing acknowledgement of the injustices of colonial dispossession experienced by Indigenous peoples with ongoing national discussions about reconciliation with the TRC's Calls to Action and the City of Toronto's Statement of Commitment. 
In light of these ongoing national discussions, there are also discussions around how planning has been complicit with the exclusion and marginalization of Indigenous and immigrant communities.

\section{The 'Dark Side of Planning'}

Although this MRP starts from the assumption that there is potential for planning to facilitate Indigenous-immigrant relations and contribute to advancing reconciliation and strengthening Indigenousnewcomer relations, it is important to recognize that planning has been involved in processes of marginalization and exclusion of certain communities. The 'dark side of planning' literature highlights that conflict and power will always be at the centre of democracy (Flyvbjerg and Richardson, 2002). Planning, therefore, is about managing conflict, exploring conflicts in planning, and learning how to work effectively with conflict.

Particularly relevant to this research, mainstream planning tools of state-based planning have continued to replicate conflict and the effects of settler colonialism in Canada, New Zealand, and Australia (Porter and Barry, 2016). In Canada there have been attempts to use physical space to oppress marginalized groups such as Aboriginal, Black, and Japanese communities; therefore, racialized spaces and mainstream groups or institutions have an impact the uneven development of racialized people in their communities (Teelucksingh, 2006). For example, red-lining practices that segregated different ethnic groups by restricting real estate within geography-specific boundaries or Japanese internment camps in British Columbia (Teelucksingh, 2006). For Indigenous communities, contemporary planning tools and practices have not always reflected Indigenous traditions and perspectives on how we manage land and resources, which were created in the colonial era (OPPI, 2019). These mechanisms and practices create the conditions for the dispossession of Indigenous peoples, as they takes away their security and access to land (Porter \& Barry, 2016). An example of this process includes Indigenous peoples' removal, resulting in disrupting the memory of Indigenous places of settlement, cultural sites, and resources. In its place, colonial architecture, places of worship, parks, lot surveys, and street patterns were constructed, all modelled after settler architecture and spaces (Matunga 2013).

Tomiak (2017) argues that settler states continue to pursue the transformation of Indigenous land into settler property and to govern Indigenous place-making and self-determination in cities. In the current context of urbanization and growing urban populations, planners are challenged to think about how their practices and profession transform land into commodities. Walker (2017) discusses how structural violence continues to take form in unequal balances of power and resources that continue to repress Indigenous peoples. Walker (2017) further explains that if planners look past Indigenous sovereignty and territoriality, condone harmful ignorance, and only see Indigenous peoples as stakeholders, then planners will reproduce structural violence. 
Planners thus continue to replicate the conflict between Indigenous and non-Indigenous communities when power is in the hands mainstream of state-based planning. Sandercock (2004) explains how the process of city-building and the clearing of regions required the ordering of urban and regional space through a range of spatial mechanisms of power such as the laws of private property; the practices of surveying, naming, and mapping; and the procedures of urban and regional planning.

Sandercock (2000) also suggests that the planning profession has historically struggled to manage life in cities of difference. Planning for diverse ethnocultural groups, including newcomers is difficult when the planning system represents the values and norms of the dominant (Western) culture (Dean et al. 2018). Dean et al. (2018) further explain how this is evident in the creation of population projections and density targets when initial assumptions about family size and the number of children per household are based on the single-family style living common in Western cultures rather than multi-generational style seen in many South American and Asian cultures. Also, community fears over difference (racism, xenophobia) are expressed through opposing places of worship or cultural community centres and ultimately make the planning system a tool for minimizing difference (Sandercock, 2000 in Dean et al. 2018).

For immigrant communities, as Tuohy \& Talen (2017) describe, urban planning and design to support immigrant neighborhoods are challenged by a lack of comprehensive federal immigration reform and the increasing significance of legal status in immigrant lives and communities. In Canada, jurisdiction over immigration is administered at the Federal level, however immigrant intergration occurs at the local level. The federal government relies on many immigrant settlement and integration programs and their implementation on community organizations and municipalities. Tuohy \& Talen (2017) argue that there are ways that the design and planning of the built environment play a role in the daily lives of undocumented immigrants including addressing restrictions on movement, increased susceptibility to segregation, and a need for engagement that is inclusive and nonthreatening for undocumented immigrants.

Planning has had a history of supporting the dispossession of Indigenous lands while also struggling to manage diversity in cities. As a result of ongoing national discussions about reconciliation, the planning profession seems to have begun acknowledging the history of mainstream state-based planning. The planning profession is shifting away from how it has been previously complicit with the exclusion and marginalization of Indigenous and immigrant communities. In 2019, this shift occurred with both the Canadian Institute of Planners and the Ontario Professional Planners Institute releasing policy statements acknowledging the important role of advancing reconciliation. 


\section{Reconciliation and Planning in Canada}

In light of the history of the dispossession of Indigenous peoples and other marginalized groups, Canada's provincial and national professional planning bodies have started discussions around the TRC Calls to Action and reconciliation. The Canadian Institute of Planners (CIP) acknowledges that many goals of Canada's Indigenous communities intersect with planning concerns including preserving language and culture, building governance and planning systems, focusing on healthy communities, ensuring sustainable resource management, establishing self-reliant communities, managing sustainable food and energy systems, and improving community housing and infrastructure. In 2003, the CIP established the Indigenous Community Planning Committee (ICPC) in order to build capacity and support for indigenous planning and community development across Canada (CIP, 2019). The CIP also acknowledges that the TRC Calls to Action address the various bodies that planners work for, and as such, planners have an opportunity to advance the TRC Calls to Action through their work (CIP, 2019). In 2019, the CIP released a policy statement on Planning Practice and Reconciliation that defines the role that planning and planners should play in reconciliation. As a whole, this document indicates that Canada's professional planning body is essential to integrating reconciliation into planning, the work of practicing planners, and participating in the broader and long-term processes of reconciliation.

At the provincial professional level, the Ontario Professional Planners Institute (OPPI) recognizes its responsibility to participate in the national discussion on truth and reconciliation and to respond to the TRC Calls to Action (OPPI, 2019). On March 23, 2018, the OPPI Council invited researchers and Indigenous elder to contribute to an Indigenous Planning “Generative Discussion." A task force was created and over the course of the next year, a report was produced establishing context and outlining recommendations for moving forward respectfully and in collaboration with Indigenous Peoples, communities, and planners. Together, the document's recommendations outline the impacts and history of colonial policies on Indigenous peoples, and demonstrate that planning has an important role in working alongside Indigenous peoples, planners, and communities to play a role in reconciliation.

Viswanathan (2017) discusses how a shared path of reconciliation may have less to do with seizing lost opportunities and more to do with fostering an openness to redefine our relationships with each other as settlers and Indigenous peoples as well as make transparent our responsibilities and accountability to each other. Walker (2017) argues that cities in Canada can lead the way for reconciliation among people, which would have to include Indigenous worldviews, protocols, goals, processes, and expertise that will take their own form in planning theory and practice. Understanding that the national and provincial planning professional body acknowledge the role planning has in reconciliation and responding to the goals of the TRC Calls to Action is very important. This is a signal 
that planners and the institutions they work within (e.g. municipalities) should lead the way to advance the Calls to Action alongside Indigenous leaders and communities.

Therefore, the leadership and guidance of Indigenous communities is a crucial step for planning to advance reconciliation. This is an opportunity for municipal planning divisions and staff to form relationships and build trust with Indigenous urban organizations and newcomers to further advance Indigenous-newcomer relations through reconciliation-focused initiatives. The role of Aboriginal community organizations, with their newcomer partners, and the constitutive role of urban spaces of interaction in cultivating relationships is crucial (D'Arcus, 2010; MacKenzie et al., 2012; Routledge, 2010 in Gyepi-Garbrah et al. 2014).

\section{Role of Municipalities in Managing Differences and Supporting Co-Existence, Diversity and Reconciliation}

In cities, people share spaces with those who may not have the same backgrounds and we must find ways of co-existing in these spaces, from the next-door neighbour to the street, neighbourhood, city and region (Sandercock, 2000). Cross-cultural understandings and communication enable all marginalized inhabitants to use their collective powers to oppose various forms of oppression. As Gyepi-Garbrah et al. (2014) state, "there is great potential for building intercultural relationships among Indigenous peoples and immigrant newcomers as a means of decolonising Western cities" (p. 1). Indigenous resurgence and immigrant mobilizations could collaborate in transforming existing spatial production and place-making to work towards the same goals of creating inclusive and just cities (Nejad, 2019). Cross-cultural dialogues can provide a common space for self-reflection, listening, and learning from the multiple histories, experiences, and narratives that remain unheard in the mainstream (Mitra, 2011). As a result, place-making would play an important role for these cross-cultural dialogues to occur in cities, as they provide a platform for collaboration between Indigenous and newcomer groups.

Therefore, understanding the importance of cross-cultural dialogue between Indigenous and newcomer groups will help identify areas of opportunity within place-making and city planning. Indigenous community-based organizations and Indigenous-led projects and initiatives are an important part of planning and advancing reconciliation and thus critical to moving forward and leading Indigenousnewcomer relations. Planners have a skill set that allows them to be collaborators, facilitators, and communicators to support city planning in the process of helping with cross-cultural dialogue and further collaboration with Indigenous-led community organizations in cities. Reconciliation will require meaningful relationship and trust building in order to start any city planning process between Indigenous and non-Indigenous peoples. 
Municipalities are important stakeholders and decision makers in working for their citizens and addressing the needs of all communities, and they play an integral role in policy implementation. As such, municipal planning could play an important role in facilitating Indigenous-newcomer relations, as illustrated through the Dialogues Project in Vancouver discussed earlier. For example, the City of Toronto divisions work to deliver immigration integration programs and services at the Newcomer Office, seek advice from the Indigenous community with the Indigenous Affairs Office to provide cultural events and grants to communities and non-profit groups with the Economic Development and Culture division and so on.

Municipalities face many issues when it comes to city management, policy, and the maintenance of quality of life. Federal and provincial governments have many different priorities and portfolios compared to municipal governments, and they perform many functions, especially when it comes to city planning and immigrant settlement and integration. However, with all these responsibilities, municipalities are faced with more demand from residents, pressures from their constituents, and have limited budgets to work with. Fawcett et al. (2015) argue that collaborative governance arrangements between municipal governments and Indigenous leaders and organizations with representative legitimacy could potentially benefit both urban Indigenous groups and local governments through mutual learning and shared responsibility. Barry (2012) as cited in Fawcett et al. (2015), concludes that institutional structures such as municipal governments will need to be modified to make long-term collaborative planning possible between Indigenous and non-Indigenous urban communities for a better-balanced surface of power relations.

Municipal relations with Indigenous communities living on or off reserve are also important to understand. Fraser \& Viswanathan (2013) examine the role of municipal planning in relation to the duty to consult and conclude that municipal-First Nations engagement will require both legislative change and a cultural shift in how planning is done and in is included in professional planning curriculum. McLeod et al. (2017) analyze the content of the 2014 Provincial Policy Statement (PPS) of Ontario in order to evaluate the relative capacity to recognize the rights of Indigenous peoples. McLeod et al. (2017) conclude that changing public perspectives will be critical to this process, and planning policies, including the PPS, can have a vital and transformative role in building dialogue and ensuring more equitable planning futures in the province of Ontario. McLeod et al. (2017) argue that a shared planning approach can garner greater public understanding and recognition of Indigenous peoples' continued interest in the land and ensure that Indigenous peoples can actively define issues and solutions through mutual understanding and mutual learning as partners. This process means that there is a meaningful willingness on the part of non-Indigenous people to break with embedded cultural assumptions, understandings, relationships and ways of doing urban planning (McLeod et al. 2017). 
Indigenizing ${ }^{13}$ city planning processes can be transformative and contribute to reconciliation. Fawcett et al (2015) argue for the need for the cultivation of a municipal culture of coexistence and coproduction between Indigenous and non-Indigenous communities in Saskatoon and other Canadian cities facilitated by the municipal government through institutionalized collaboration with Indigenous organizations, leaders, and communities.

Brock (2009) argues that municipalities must create community dialogue around issues of diversity, immigration and multiculturalism is important. Governments and staff, therefore need to look at strategies for the creation of long-term engagement in cross-cultural dialogue between members of the host society and immigrant populations. Senior levels of government, particularly federal governments, are usually the drivers behind immigration policy and the creation of opportunities for new immigrants to come to Canada and other polyethnic nations (Brock, 2009). As part of their responsibility for implementing this strategy, senior levels of government need to focus energy and resources on effectively co-integrating new immigrants and current residents. To accomplish this, they need to explicitly support programming in cities that attract the most immigration (Brock, 2009). This would be a vital step towards creating an environment conducive to effective immigrant settlement and integration including learning about the history and current context of Indigenous peoples and communities.

The training of public service staff is also an important tool that cities can utilize, as the TRC Call to Action \#57: Professional Development and Training for Public Servants suggests. To be effective, diversity training and cross-cultural communication initiatives must create long-lasting changes in people's behaviour (Brock, 2009). Rather than merely focusing on rights and responsibilities, this pedagogical approach focuses on developing critical insights into issues of power and inequality (Brock, 2009). Increasingly, in planning discourse and other literature on social change, the transformational role of stories and storytelling is explored especially through community arts, undertaken with a community engagement approach, offering unique opportunities to create dialogue between groups (Brock, 2009).

Sandercock (2003) states that if multicultural cities are to be socially sustainable, their citizens, city governments, and city-building professions need to work collaboratively on citizenship, urban policies, social policy, commitment of political parties, and so on. In Toronto, municipal policies - not local elections - have been the prime promoters of immigrant incorporation (Siemiatycki, 2011). However, through the years, city councils, though not reflective of the ethnocultural diversity of Toronto

13 Indigenization recognizes the validity of Indigenous worldviews, knowledge and perspectives. Indigenization identifies opportunities for indigeneity to be expressed. Indigenization incorporates Indigenous ways of knowing and doing. Indigenization requires non-Indigenous people to be aware of Indigenous worldviews and to respect that those worldviews are equal to other views. Indigenization is about incorporating Indigenous worldviews, knowledge and perspectives into the education system, right from primary grades to universities (Indigenous Corporate Training, 2017). 
have demonstrated a strong commitment to proactive, inclusive policies related to immigration and diversity (Siemiatycki, 2011).

Overall, the growing population of Indigenous and immigrant newcomers in Canadian cities presents a new challenge for municipalities. At the same time, there is increasing acknowledgement of the injustices of colonial dispossession experienced by Indigenous peoples, as indicated by the TRC. In addition, the planning profession and practice have been complicit with the exclusion and marginalization of communities including Indigenous peoples and newcomers in settler states. As a result, the planning profession seems to be acknowledging this history and engaging with the TRC Calls to Action and the reconciliation discourse, as illustrated by the CIP and OPPI's policy statements on Indigenous perspectives in planning. In light of the topics previously discussed, there is a role for municipal planning in further advancing reconciliation in regard to supporting and strengthening Indigenous-newcomer relations. This leads to the analysis of what the City of Toronto is currently doing after it has committed to engaging with Indigenous peoples through the Statement of Commitment to Aboriginal Communities in Toronto and with the TRC Calls to Action.

\section{CHAPTER FOUR: DOCUMENT SCAN ANALYSIS}

To explore and understand how the City of Toronto is or is not committing to the TRC Calls to Action, a scan of selected policy documents and City initiatives, and semi-structured interviews were conducted with City staff. These qualitative data collection methods utilized selective coding to explore how the City is working towards advancing reconciliation and/or Indigenous-newcomer relations. The documents, initiatives, and initial interviewees were chosen from publicly available information on the City's website.

\section{Document Scan}

The document scan examined specific City documents to identify whether or not the City is responding to the TRC Calls to Action through the broader policy direction expressed in those documents. I specifically focused on community engagement, policy, divisional strategies, and urban planning and design guidelines. The documents were chosen after scanning the selected divisions on the City of Toronto's website for specific documents related to key themes that I have identified (See appendix $\mathrm{C}$ and $\mathrm{D})$. The document scan identified key trends and categories, and indicates the City's policy directions. 
Overall key trends identified in the document scan include:

1. Differences between city-wide and local documents: There is a difference between broader city-wide policy versus geography-specific policy in terms of how they address specific policies, objectives, and language. For example, broader City policies in the Official Plan used terms such as "vulnerable groups" and "equity-seeking groups" when discussing target communities of focus. On the other hand, the TOCore: Downtown secondary plan - which focuses on downtown only - made explicit reference to the TRC Calls to Action, the Statement of Commitment, history, and culture. This suggests that local policy documents such as secondary plans or community engagement plans are more specific in their goals and objectives in more defined areas.

2. Indigenous or newcomer-specific documents: There are Indigenous-specific documents such as the Meeting in the Middle Engagement Strategy and newcomer-specific documents such as the Newcomer Strategy. No explicit plan or policy that focused on or mentioned Indigenous-newcomer relations. At the municipal level in Toronto, while there are government-led initiatives directed toward Indigenous and immigrant communities within different divisions/departments, as separate groups, a collaborative approach has not been evident between the two communities at this point in time.

3. Importance of Indigenous consultation and engagement: Specific documents mention the importance of consulting and engaging with Indigenous communities on projects. However, there was no mention of engagement with newcomer groups.

\section{Policy \& Legislation}

\section{Official Plan}

This section focused on overarching and geographic-specific planning policy and legislation that showcase the differences between city-wide policy and geographic-specific policy. The Official Plan is administered by the Toronto City planning division, which oversees how the city of Toronto is planned through strategic visions, goals, and policies (City of Toronto, n.d). The latest consolidated update for the Official Plan was released in February 2019. The analysis identified that the Official Plan uses broad terms such as equity-seeking groups and vulnerable populations/groups/users when referring to target community areas in policies. However, given the broad scope of the Official Plan's vision, there is rarely any mention of specific groups such as Indigenous or newcomer unless it relates to arts and culture spaces for example, The contributions of Toronto's diverse cultures will be considered in determining the cultural heritage value of properties on the Heritage Register. (Official Plan, Chapter 3, page 12). This 
relates closely to Indigenous groups identifying culturally significant sites such as the "The Core Circle" in the TOCore: Secondary Plan that will be elaborated on. Instead broad statements are used in the Official Plan and suggest broader groups that fit within equity-seeking groups or vulnerable populations or do not mention any specific group. For example, the opening chapter states that Toronto is "a City of Diversity \& Opportunity [where] multiculturalism is celebrated, and cultural diversity supported" (Official Plan, Chapter 1, p. 3). The City of Toronto often showcases and highlights the diversity of the city in introductions in documents; however, further explanation of the kind of cultural diversity and multiculturalism is not given This shows that city-wide policy is broad in its descriptions of specific ethnocultural groups and communities, as it emphasizes overall cultural diversity. Secondly, the Official Plan rarely makes any mention of Indigenous and newcomer groups in their policies and objectives within the Official Plan unless it relates to defined geographical areas (i.e. the Cultural Heritage Landscape and the TOCore: Downtown Secondary Plan).

\section{TOCore: Downtown Secondary Plan}

The TOCore: Downtown Secondary Plan (TOCore) is a downtown-specific plan that sets out vision, goals, and policies for growth in Downtown Toronto (City of Toronto, n.d.). The TOCore is administered by the City Planning division and on June 5, 2019, the Minister of Municipal Affairs and Housing approved the Official Plan Amendment No. 406 (the Downtown Plan). In stark contrast to the Official Plan, this secondary plan makes explicit reference to Indigenous peoples and focuses heavily on ensuring Indigenous history and culture are celebrated in downtown public spaces and the built environment. As McLeod et al. (2017) state, "changing public perspectives will be critical to planning policies in building dialogue and ensuring more equitable planning futures in the province of Ontario (p.84) The TOCore is a great example of how the dialogue and focus are shifting in City Planning and other divisions on advancing reconciliation initiatives. The plan specifically makes references to integrating Indigenous placemaking into the 'Core Circle' to advance reconciliation through placemaking and other initiatives. The quote gives a detailed description of how City Planning intends to ensure that Indigenous cultures are reflected through Indigenous placemaking:

\footnotetext{
The topographic and natural features of Toronto - including the Lake Ontario shoreline, Toronto Islands, Lake Iroquois escarpment, Don River Valley and Rosedale Valley Ravines, and the Garrison Creek watershed - form the natural setting within which Downtown is situated. The Core Circle builds on Toronto's identity as a "city within a park" and provides opportunities to acknowledge and reinforce its history and natural setting. These natural and topographical features provide a link to the millennia-old Indigenous cultures of this region. They preserve aspects of the character of the pre-colonial landscape that are considered sacred to Indigenous peoples. Integrating Indigenous placemaking into the Core Circle is an opportunity to advance reconciliation... Toronto's identity as the traditional territory of the Huron-Wendat Confederacy, the Haudenasaunee Confederacy, the Mississaugas of the New Credit First Nation and the
} 
Métis people, and home to many diverse Indigenous peoples is reflected and celebrated in Downtown's public spaces and increasingly in its built environment (City of Toronto, p. 3)

The quote above is significant because of its explicit mention of advancing reconciliation by integrating Indigenous placemaking. The TOCore is responding to the Statement of Commitment's pledge to improve public awareness of Aboriginal life in Toronto. Secondly, specific sites within the downtown area were chosen for placemaking that acknowledges Indigenous cultures and histories. In the TOCore, there is a policy that explicitly states that Indigenous cultures and histories must be acknowledged. Dor example, "A Walkable Downtown [should]. reinforce historic public spaces, including those that acknowledge Indigenous cultures and histories" (City of Toronto, p. 34) and "the Queen's Park and Civic Precincts: 7.27. The Queen's Park and Civic Precincts will incorporate placemaking that acknowledges Indigenous cultures and histories" (City of Toronto, p. 27). In the next quote, this specific policy in TOCore lays out different land use typologies that can support community hubs for culture and community spaces, such as an Indigenous community hub, like the Indigenous Centre for Innovation and Entrepreneurship which will be elaborated on. For example, "the co-location and/or creation of community hubs for cultural and community spaces, including Indigenous organizations, will be encouraged as part of development where appropriate in Mixed Use Areas 1, Mixed Use Areas 2, Mixed Use Areas 3, Mixed Use Areas 4 and Regeneration Areas" (City of Toronto, p. 56).

The mention of including Indigenous culture and histories in policy is significant because it is a clear sign that City Planning is acknowledging the City's Statement of Commitment and the TRC Calls to Action. It is also interesting to note that the interests of Indigenous people exist under the "Cultural Spaces" section of TOCore, which defines Indigenous interests as in the realm of culture only. The mention of and focus on Indigenous people are important because it shows an emphasis on reflecting and showcasing Aboriginal life in Toronto. The document also specifically mentions the importance of partnership and collaboration with Indigenous communities. This quote signifies that City Planning acknowledges that partnerships and collaboration with Indigenous communities are encouraged and go beyond the duty to consult. This quote also shows that the TOCore is also responding to the City's commitment to explore ways to strengthen the capacity of Aboriginal organizations and associations to plan, lead and deliver initiatives for local Aboriginal communities. This is a great example of a municipality going beyond the tokenism of consultation to participate in planning, design, and development, allowing Indigenous communities to take more control in a direction they best think would fit. For example, "Partnerships and collaboration with Indigenous communities will be encouraged in the planning, design and development of parks and the public realm" (City of Toronto, p.32). 
As a whole, the TOCore is a Downtown-specific secondary plan that meaningfully acknowledges and addresses Indigenous cultures and histories as an important factor that aims to advance reconciliation through Indigenous placemaking. The TOCore document suggests that City Planning is committed to achieving the City's Statement of Commitment and reflect aspects from the priority TRC Calls to Action on advancing reconciliation. The City explicitly states that Article 11 of the UNDRIP states that Indigenous peoples have the right to practise and revitalize their cultural traditions and customs including the right to maintain, protect and develop the past, present and future manifestations of their cultures. This is significant because City Planning is ensuring that Indigenous placemaking is an important aspect of TOCore by making Indigenous cultural traditions and customs visible through the built environment. As a result, the public's awareness of the history and cultures of the Indigenous peoples of Toronto are present. TOCore, once successfully implemented in full, can be a precedent for many other secondary plans in the future, which will be further discussed when the Chief Planner states areas of interest such as the Secondary Plan of the Jane-Finch corridor, which has a significant amount of immigrant population and Indigenous heritage and history.

\section{Community Engagement}

\section{Meeting in the Middle Indigenous Engagement Strategy}

The Meeting in the Middle Indigenous Engagement Strategy can be categorized as a reconciliation-focused document and was co-created between the City of Toronto division Shelter Support and Housing Administration (SSHA) and Indigenous leaders to establish a plan to address Indigenous homelessness in Toronto in 2018. The vision of the engagement strategy is to meaningfully address Indigenous homelessness in Toronto (City of Toronto, n.d.). The strategy is divided into two parts (Honouring the Relationship and Upholding the City's Statements of Commitment to the Aboriginal Communities of Toronto) with the last section specifically focusing on implementing actionable items that uphold the City's Commitment to the Statement of Aboriginal Communities. For example, the Strategy includes actionable items that City staff can incorporate into their daily work, such as "as SSHA staff, I will: Seek out Indigenous perspectives to grow my understanding of Canada's true history with First Nations, Inuit and Métis people; so that I might better see colonization's impacts on urban Indigenous communities in Toronto" (City of Toronto, p. 9). Similarly, the strategy mentions in the appendix that leaders who were part of a three-day engagement and action planning session to create this Strategy were tasked with evaluating their familiarity with the TRC Calls to Action.

In this document, we can see a City strategy that explicitly engages with the spirit of the TRC by developing concrete actions that the City, SSHA, and Indigenous organizations have agreed upon. 
However, this specific strategy is only targeted toward the SSHA Division when engaging with Indigenous communities and is not a city-wide Indigenous engagement plan. Engagement strategies emerged as a common thread in interviews with staff. I will further discuss how the City's Economic Development and Culture division is currently working on an "Indigenous Engagement" strategy and how City Planning is inquiring into the possibility further. The Meeting in the Middle Indigenous Engagement Strategy has also been identified in several interviews conducted with City staff from the Indigenous Affairs Office; Economic Development and Culture; and Parks, Forestry, and Recreation. Overall, the engagement strategy seeks to address goals set out in the Statement of Commitments to Aboriginal Communities and the TRC Calls to Action, even if regarding a specific policy area - decision making related to Indigenous homelessness in this case. The strategy also mentions and emphasizes Indigenous history and culture in a meaningful way when addressing Indigenous homelessness. For example, Commitment 1 of the Strategy addresses that the "City commits to creating training opportunities for the Toronto Public Service to learn about the history and its current day impacts from Aboriginal Elders and other Aboriginal partners. The City also commits to working with Aboriginal communities to improve public awareness of Aboriginal life in Toronto" (City of Toronto, p. 13). Perhaps not surprisingly, since it is an Indigenous engagement strategy, there is no focus on or mention of non-Indigenous peoples, including newcomers or immigrants, in the strategy.

\section{Urban Design \& Planning Guidelines}

\section{George Street Revitalization Project - Streetscaping Plan}

The George Street revitalization project (GSR) streetscaping plan introduced on May 18, 2018 is administered by the public realm section of transportation services and is closely related to reconciliation initiatives. This is the first plan from the documents I have analyzed that explicitly states that the GSR would take into account the Principles and Calls to Action of the TRC and address reconciliation rather than the Statement of Commitment. The GSR is co-sponsored by the Support and Housing Administration and Long-Term Care Homes and Services Divisions in collaboration with City Planning and Parks, Forestry, and Recreation to create a significant opportunity for Indigenous placemaking in the downtown urban fabric and to celebrate and honour Indigenous culture as another step toward reconciliation. In the comments section, the TRC definition of reconciliation is also provided, which has not been seen in any previous documents in this study. Additionally, this plan explicitly states that it takes into account the TRC Calls to Actions: 
In recognizing the historic Indigenous presence in the area, the design of the streetscape for the George Street Revitalization project would explicitly take into account the Principles and Calls to Action of the Truth and Reconciliation Commission. Recognizing the historic presence of the First Peoples of this land would also support George Street Revitalization (GSR) - Streetscape Plan and accelerate development of the emerging Indigenous District within Toronto and contribute to establishing a more respectful relationship with some of the most vulnerable members of our society from all backgrounds (City of Toronto, p.1)

The GSR plan also states how Indigenous communities and people would be involved in taking leadership of community consultation, design, and project management. The plan also explains explicit actions on how the City intends to have Indigenous consultants undertake project management leadership; for example, "to engage Indigenous consultants to undertake community consultation, design and review activities and to amend the scope of work and fees for the GSR consultants" (City of Toronto, p.3). This process of involving Indigenous consultants will be further discussed in relation to the role of the Indigenous Affairs Office and how community partnerships with Indigenous organizations such as Toronto Aboriginal Social Services Council (TASSC) are important. The GSR then discusses how recognizing the historic Indigenous presence, which addresses the public realm that addresses safety issues, security, and mobility. The GSR explains that Indigenous place-making initiatives will enhance public awareness as well as public safety; for example, "recognizing the historic Indigenous presence and the relationship to some of the most vulnerable members of our society, such improvements to also address safety, security and mobility and create more pedestrian-friendly, liveable streets" (City of Toronto, p.2). This explains how the City is currently responding to the Statement of Commitment and TRC Calls to Action in regard to reconciliation and increasing public awareness of Indigenous culture and history. The objectives section of the Planning, Design and Development of Parks and the Public Realm include explicit reference to TOCore policies that include celebrating Indigenous histories recognizing cultural and natural heritage and supporting Indigenous cultural and ceremonial practices. For example, policy 7.3.3. in the TOCore: states [that the plan will] "celebrate Indigenous histories and recognize cultural and natural heritage through place-making, naming, wayfinding, monuments, interpretive features, public art, partnerships and programming" (City of Toronto, p. 22) and "7.3.4. support Indigenous cultural and ceremonial practices through the provision of programmable spaces" (City of Toronto, p. 23).

The specific examples listed above show concrete ways in which the City is taking policy directions on tackling Indigenous issues by integrating them into city planning and the design of parks and public spaces. This trend indicates that City divisions such as City Planning; Parks, Forestry, and Recreation; and Economic Development and Culture are interpreting the Official Plan and TOCore to support work that encourages the TRC Calls to Action and Statement of Commitment. The GSR, once completed, will be a significant project that will raise public awareness and encourage Indigenous-led 
project management and design. It will be interesting to see if future City Planning projects that replicate Indigenous-led leadership for Indigenous place-making. Still, the GSR and TOCore documents are signalling that City Planning; Parks, Forestry, and Recreation; and Economic Development and Culture are receptive and willing to work on advancing reconciliation. This shows that with enhancing public awareness can help educate non-Indigenous people including newcomers in Toronto. Education through Indigenous place-making in the built environment can strengthen relationships and understanding between non-Indigenous and Indigenous people. This trend indicates that City divisions are interpreting the Official Plan and TOCore to support work that encourages actions towards the TRC's Calls to Action and the Statement of Commitment. As mentioned earlier in the OPPI Indigenous Planning Perspectives Tasks Force Report (2019) contemporary planning tools and practices have not always reflected Indigenous traditions and perspectives; therefore, the GSR and TOCore are examples in which City Planning and other divisions are working to support and reflect Indigenous traditions and perspectives in Toronto.

\section{Divisional Strategies}

\section{Indian Residential School Survivor (IRSS) Legacy project - Report to Action}

The Indian Residential School Survivor (IRSS) Legacy Project Report to Action from June 27, 2018 from Economic Development and Culture and Facilities Management specifically relates to reconciliation and Indigenous place-making initiatives (City of Toronto, n.d.). The report to action mentions how the City Council endorsed all the TRC Calls to Action and directed staff to develop concrete action to fully implement all calls to action that explicitly recognize the role of municipalities. The IRSS Legacy Project is specifically responding to Call to Action 82 to create a highly visible monument to recognize Indian residential school survivors. This specific project is also reclaiming and helping support an Indigenous resurgence back into the built environment and public realm (City of Toronto, n.d.). As Matunga (2013) described, colonial architecture, places of worship, parks and streets removed the memory of Indigenous places of settlement and cultural sites. This project is significant because it will be a major milestone for Indigenous place-making as the site will be built in front of Toronto City Hall's Nathan Phillips Square. This site is a major gathering spot for Torontonians and is highly visible in downtown Toronto. This project is also symbolic of its location in front of City Hall as it supports the Indigenous cultural resurgence back into the built environment. Only recently has Nathan Phillips Square supported Indigenous place-making with the recent addition of the Medicine Wheel on Toronto's iconic City sign at Nathan Phillips Square. The Square has been identified as a site in partnership with the Toronto Council Fire Native Cultural Centre to lead the process. Overall, this report 
mentions how the project will contribute to the City's efforts to advancing reconciliation and responding to the Call to Action 82:

In December 2015, City Council endorsed Truth and Reconciliation Commission of Canada's (TRC) Calls to Action and directed City staff to develop concrete actions to fully implement all calls to action that explicitly recognize the role of municipalities. Call to Action 82 was identified as one that recognized the role of municipalities. Call to Action 82 calls for the commission and installation of a publicly accessible and highly visible monument in each provincial or territorial capital to recognize Indian residential school survivors (City of Toronto, p.1).

The project illustrates how policy and vision are being implemented through action and collaboration between different municipal divisions such as Parks, Forestry, and Recreation; Economic Development and Culture; and the Indigenous Affairs Office. This collaboration supports Sandercock's (2000) notion of planners in 'managing difference' as the work of negotiating fears and anxieties, mediating memories and hopes, and facilitating change and transformation between different cultural groups in our cities. As described in the quote below, the City Council directed City staff to work in partnership:

An IRSS Legacy project working group has been established in order to achieve these objectives. The working group is led by EDC working with Facilities Management, the City's Indigenous Affairs Office and the Equity, Diversity and Human Rights Division. Other members include those with roles in Indigenous relations and place-making in the City, such as Parks, Forestry and Recreation, and Planning (City of Toronto, p. 6)

Specific reference to advancing reconciliation has also been noted in the report to action, which has explicitly mentions Indigenous-led leadership to set the objectives and goals around reconciliation and Indigenous place-making:

Given the significance of the project for Toronto Council Fire (TCF), the City and all Torontonians, EDC is working closely with the Indigenous Affairs Office and the Equity, Diversity and Human Rights Division, seeking to ground the project in common objectives around reconciliation and Indigenous place-making. The proposed project represents a significant symbolic gesture of reconciliation by the City of Toronto, and the project's ultimate design, maintenance and programming must therefore serve the City's commitment to advancing reconciliation (City of Toronto, p. 6).

The potential of the IRSS project has also been mentioned by several interviewees from the Newcomer Office, Economic Development, and the Indigenous Affairs Office, who described the potential of the IRSS project and its strategy towards education and programming in terms of Indigenous-newcomer relations and thus it will be further discussed. Outlining specific education goals and programming will help assist with the Statement of Commitment's goals and TRC Calls to Action:

Given the origins of the project with the TRC, the project can contribute to raising public awareness of the legacy of Residential Schools as well as highlighting the resilience of Indigenous peoples in the face of such challenges. TCF has outlined an overall programming vision, where the primary intention of the 
project is to be an inclusive space for teaching, learning, sharing and healing. The space is designed to enable Indigenous and non-Indigenous people to come together to learn about residential schools, their legacy and to work toward reconciliation... This vision sees the Indigenous community, under the stewardship of TCF, as having a primary role in programming the space, and also provides opportunities for the City and other partners to program the space. These programming partnerships will be coordinated through the creation of a co-management agreement between the City and TCF (City of Toronto, p. 6).

Overall, this project highlights the importance of raising public awareness of Indigenous histories and cultures through Indigenous place-making. This project also suggests that Indigenous-led leadership and cross-divisional collaboration will be integral to delivering initiatives with similar goals.

\section{Fulfilling Calls to Action from the Truth and Reconciliation Commission Report - Report to Action}

The Fulfilling Calls to Action from the Truth and Reconciliation Commission Report (TRC, 2015) from April 1, 2016 from the City Manager which includes all wards explicitly stating the Statement of Commitment to Aboriginal Communities of Toronto and the TRC Calls to Action in this report. The report provides an update on the eight Calls to Action identified by the city related to health, reconciliation, professional development and training, museums and archives, the National Centre for Truth and Reconciliation, commemoration, sports and reconciliation, and newcomers to Canada followed by specific city action. For example, the City adopted the United Nations Declaration on the Rights of Indigenous Peoples (UNDRIP) as part of its year-long proclamation on Truth and Reconciliation in 2013. The progress of these eight actions is a part of the annual staff update to the City Council on the Statement of Commitment to the Aboriginal Communities of Toronto that is released every year. This suggests that the City is keeping track of and measuring how they are achieving the actions each year. However, as of 2020, there have not been any updates made available to the public.

\section{Toronto Newcomer Strategy Plan and Progress Report - 2016}

The Toronto Newcomer Strategy was released in 2013 by the Social Development, Finance, and Administration Division. The strategy mentions how the city is one of the most multicultural urban areas in the world and how diverse cultures and communities have helped establish Toronto's identity as a vibrant global city (City of Toronto, 2016). The strategy also mentions how integration into the city's social, economic, and cultural landscape is difficult for many newcomers. Overall, the strategy is informed by strategic pillars, local immigration partnerships, and a newcomer leadership table. There is also no mention of the Statement of Commitment or the TRC Calls to Action. However, in the initiative scan and interview with Senior Policy Advisor 1 and Community Development Officer 1, increased interest is shown in newcomers and strengthening and building relationships between Indigenous peoples and non-Indigenous newcomers. This suggests that the policy is broader in the focus areas; however, there is an opportunity and interest from the Newcomer Office to work on Indigenous-newcomer 
relations. From this document scan, it is unclear if the Toronto Newcomer Strategy Report supports the Statement of Commitment or Calls to Action. However, as further discussed in the following sections, there is a willingness to work on strengthening relations, but for now it is in the very early stages.

Interestingly, however, in the Toronto Newcomer Strategy Progress Report (2016) there is a shift in adding an Indigenous focus to the actions of the Newcomer Strategy. The progress report makes explicit mention of further developing "Toronto For All” public education initiative ${ }^{14}$ to specifically address transphobia and issues experienced by Indigenous peoples which will be further discussed in the initiative analysis and interview analysis section. This suggests that the Newcomer Office is in the early stages of furthering documents that will help create and sustain Indigenous-newcomer relations in the future. There is an opportunity for an updated version of the Strategy that includes Indigenous history and culture as a focus area for newcomers. The Open Forum on Indigenous-newcomer relations hosted by the Newcomer Office will be elaborated on in the initiative scan and interview with Community Development Officer 1. This change in emphasis from the original release of the Strategy in 2013 to the report in 2016 is significant, as it suggests there has been a shift in interest to include Indigenous perspectives in newcomer-related initiatives and policies.

Overall, the document scan looked at specific City documents to identify themes that indicate the policy direction for City divisions and staff to interpret policies relating to implementation of the Statement of Commitment and the TRC Calls to Action. In reading through the documents, some key trends surfaced, including differences between how broader and geography-specific documents engage with Indigenous peoples or newcomers and the fact that Indigenous or newcomer specific documents tend to indicate the current policy direction of the City. The TRC Calls to Action and the Statement of Commitment have been referenced in the GSR Plan and TOCore but have still have not been mentioned in any divisional strategy or the Official Plan. These trends suggest that there is a shift in municipal policy direction and an interest in and willingness to strengthen relationships with Indigenous people. The next section discusses the initiative scan analysis and will showcase more trends that indicate how these policy directions are actually being implemented through initiatives or projects. The TOCore and GSR documents are great examples of including the Statement of Commitment and TRC Calls to Action and making explicitly policy directions to advance reconciliation, which leads to a greater Indigenous presence in the built environment through Indigenous place-making. As a result, with greater public awareness, there is an opportunity for all citizens including newcomers to increase their knowledge and appreciation of Indigenous cultures and perspectives. The lack of specificity in mentioning Indigenous-

\footnotetext{
${ }^{14}$ Toronto For All is a public education initiative to generate dialogue among Toronto residents in order to create a city that says "no" to all forms of discrimination and racism, including systemic racism (City of Toronto, n.d).
} 
newcomer relations in these documents suggests a current barrier. The trends discussed also indicate that Indigenous and newcomer topics are siloed as of right now in the documents; however, the initiative scan and interviews will elaborate more on the potential of divisions supporting Indigenous-newcomer relations.

The next section discusses the initiative scan analysis and will showcase more trends that indicate how these policy directions are actually being implemented through concrete initiatives or projects led by different City departments.

\section{CHAPTER FIVE: INITIATIVE SCAN ANALYSIS}

The document scan helped highlight the current policy direction of the City. The purpose of the initiative scan is to identify whether identified City divisions are taking initiative on the Statement of Commitment or the TRC Calls to Action more broadly and through specific actions with any working groups/committees, consultation, events, or divisional projects. This section will explore the current level of engagement of staff with Indigenous newcomer relations and identify opportunities. Included in the initiative scan are projects/actions in the focus areas of Indigenous place-making, newcomer diversity and inclusion, and Indigenous and Newcomer Relations. The initiatives were selected from the City of Toronto website using selective coding to identify key themes (See appendix C). To qualify as an initiative, it needs to be an action such as a presentation, a report to action, a council member motion, consultation engagements or public event. The initiative scan looked at implementation and action items of initiatives that relate to identified themes in action plans, events, and committees and were categorized then based on their focus on reconciliation or Indigenous-newcomer relations.

Overall key themes identified from the initiative scan include:

1. Action is being implemented and there is interest: There are projects that directly respond to the TRC's Calls to Action and Statement of Commitment to Aboriginal Communities, such as the Indian Residential School Survivor (IRSS) Legacy project and the Indigenousnewcomer open forum. This trend suggests that divisions such as the Newcomer Office; Economic Development and Culture; and Parks, Forestry, and Recreation are responding and taking action on reconciliation-focused initiatives or Indigenous-newcomer relations. The trend also suggests that these initiatives are in the very early stages of implementation.

2. Indigenous and newcomers are included in the discussions: Indigenous and newcomer terms are used in initiative topics in comparison to the documents discussed in the previous section. However, they are mentioned separately, with the exception of the recent Indigenousnewcomer relations Open Forum hosted by the City's Newcomer Office on Thursday, 
February 20, 2020. This trend suggests that Indigenous-newcomer relations are in the early stages and that the priority so far is on advancing reconciliation and strengthening Indigenous relationships and capacity in Toronto.

3. Indigenous community organization leadership: A common trend is that the City of Toronto's Aboriginal Affairs Committee is involved with many initiatives and has given advice and feedback on City projects. The initiatives mention that they have consulted with the Aboriginal Affairs Committee.

4. Celebration of history through creativity and education: Arts and culture and education and programming are important ways to acknowledge Indigenous history and culture and communicate to the public about Indigenous peoples and history. The Newcomer Day Celebrations, Toronto for All public education campaign and the IRSS project initiative aim to increase public awareness and the presence of Indigenous history and cultures. This trend suggests that the creative and arts sectors will play an important role in the future since Indigenous-newcomer relations are in the early stages, as is indicated in the document and initiative scan further elaborated in the interview section.

5. Siloed action until now: While different actions are being implemented for Indigenous and newcomer communities, however, there had been no indication of collaboration until the Open Forum that happened in February 2020. This trend suggests that Indigenous-newcomer relations are in the early stages of implementation; however, City divisions are aware of their importance and are currently working on creating a space between the immigrant sector and Indigenous community organizations. This shows a great opportunity to make a change that could help create the capacity and energy needed to support Indigenous-newcomer relations.

\section{Aboriginal Affairs Advisory Committee Terms of Reference}

An initiative and action taken by the City was the creation of the Aboriginal Affairs Advisory Committee. The terms of reference were approved by the City Council on March 27 and 28, 2019. The Committee does not direct City staff or make binding decisions on the Toronto City Council or the City of Toronto. However, any advisory body recommendation that requires action by City officials or City Council must first be considered by the appropriate Council Committee and, when necessary, approved by the City Council. These terms of reference suggest that the City has taken direct action to ensure that Indigenous-led decision making and consultation are provided to City staff and divisional projects. This initiative of creating the Aboriginal Affairs Advisory Committee has provided opportunities for staff and divisions to meaningfully engage with advancing reconciliation and supporting Indigenous-newcomer 
relations. However, at the same time, the administrative process may be slowed if a project is considered by a Council Committee and the City Council.

\section{Indigenous Centre for Innovation and Entrepreneurship - Backgrounder \& Member Motion}

In 2012, the City began discussions about creating an Indigenous business centre and cultural district in Toronto. Following a feasibility study in 2013, a report identified key areas of importance, including keen community interest to redesign, re-envision and rethink Indigenous business and entrepreneurship within an innovative and contemporary mindset (City of Toronto, n.d.). The local Councillor Wong-Tam (Ward 13 Toronto-Centre) began working with City Planning in 2013 to identify a new development on Dundas Street East as a potential location for the Indigenous Centre for Innovation and Entrepreneurship (ICIE). Over a period of five years, with community support and through extensive negotiations with the developer, the City of Toronto secured a location (200 Dundas Street East); it has 22,000 square feet of space over three floors that will be dedicated to serving Indigenous entrepreneurs and the local Indigenous community. The ICIE will be a culturally- and technologically-rich environment to support start-ups led by Indigenous majority-owned businesses (City of Toronto, n.d.). The ICIE will also be a hub and meeting place for Indigenous entrepreneurs, industry partners, customers and more. Establishing the ICIE is an action taken by various divisions such as the Indigenous Affairs and Economic Development and Culture and will be further discussed in the interview analysis section.

The Native Women's Resource Centre of Toronto hired an Indigenous-owned firm to study the feasibility of creating an Indigenous Business and Cultural District along Dundas Street East in the downtown neighbourhood of the Garden District. Over a period of five years, with community support and through extensive Section $37^{15}$ and community benefits negotiation with the developer, the partial first and second floor of the building's podium, initially 14,000 square feet and growing to 16,000 square feet and eventually designed to be an expansive 20,000 square feet, was secured by the City of Toronto to become an incubator and co-working space dedicated to serving Indigenous entrepreneurs and the local Indigenous community. On July 23, 2018, Councillor Kristyn Wong-Tam put forward a motion for the authorization to release Section 37 (Planning Act) Funds from various developments for capital improvements to the future space for the ICIE at 200 Dundas East. This specific initiative is a good example of how the City Planning Section 37 tool has been used to benefit the Indigenous community and should set a precedent for future developments in the city, especially to support Indigenous and newcomer

${ }^{15}$ Implementation Guidelines for Section 37 of the Planning Act: The Implementation Guidelines for Section 37 of the Planning Act was adopted by City Council and was revised to adopt amendments as of January 2016 (City of Toronto, n.d.). 
communities. Municipal planning tools such as Section 37 could help further strengthening Indigenous place-making with an emphasis on increasing public awareness and education about Indigenous histories and culture. For example, public art or urban design initiatives in parks could be utilized to advance reconciliation. This initiative is still under construction, and once completed it could act as an anchor for the future Indigenous business and culture district. If a district is created, this would be an opportunity for divisions to create initiatives and programming to enhance Indigenous-newcomer relations.

\section{Our Common Grounds: Incorporating Indigenous Place-making in the city of Toronto's Parks Capital Projects Presentation}

Our Common Grounds: Incorporating Indigenous Placemaking in the City of Toronto's Parks Capital Projects (Our Common Grounds) was a presentation given to the Aboriginal Affairs Committee by City Planning and Parks, Forestry, and Recreation on November 3, 2017 (City of Toronto, n.d.). The presentation described the TOCore and planning policy to create a framework for place-making to create specific tangible projects that advance reconciliation through the built environment. The presentation states that working towards a place-making framework responds to the Calls to Action and Statement of Commitment to various one-off programmes, places and initiatives. There is no specific mention of newcomers or immigrants in the plan; however, education and programming are mentioned in the presentation. This presentation suggests that City staff in Parks, Forestry and Recreation and City Planning are in the early stages of incorporating an Indigenous place-making strategy to increase the Indigenous presence in the built environment. This would be an opportunity for these divisions to explore an Indigenous-newcomer relations initiative that could be incorporated into the strategy.

\section{Regularizing Toronto For All: A Public Education Initiative to Support Civic Resiliency - Report for Action}

Toronto For All is a public education initiative aimed at generating dialogue

among Toronto residents in order to create a city that says "no" to all forms of discrimination and racism, including systemic racism (City of Toronto, n.d.). The public education initiative advertises on public transit and through other marketing means. On September 12, 2017, the City of Toronto divisions Equity, Diversity, and Human Rights and Social Development, Finance \& Administration released a report for action on regularizing Toronto For All: A Public Education Initiative to Support Civic Resiliency (City of Toronto, n.d.). This report for action relates to reconciliation initiatives and Indigenous-newcomer relations. The report emphasizes civic resilience and raising awareness about social equity issues faced by Torontonians and equity-seeking groups. This specific initiative responds to Brock's (2009) argument that municipalities must create community dialogue around issues of diversity, immigration and 
multiculturalism. However, common campaigns that are not just advertisements on boards and public spaces are not sufficient by themselves and require cross-cultural collaboration:

The goal of Toronto For All is to generate dialogue amongst Toronto residents in order to create a city where all Torontonians say "no" to all forms of discrimination and racism, including systemic racism. Toronto For All encourages all Torontonians to challenge implicit biases, negative attitudes, stereotypes, and prejudices that contribute to systemic barriers to respect, inclusion, and equity. (City of Toronto, p. 3)

The City runs approximately 50 Toronto For All campaigns per year, and in 2017, they proposed the next two campaigns to focus on the experiences of Indigenous people and people living with disabilities. However, they stated that only one campaign would run in 2018 to focus on the experiences of Indigenous people because budget related issues and the 2018 municipal election. The City states that funding for the Indigenous campaign is included as a New Service Priority in the 2018 Operating Budget Submission for Social Development, Finance and Administration.

\section{Newcomer Day Celebrations}

First proclaimed in 2015, Toronto Newcomer Day is an annual event held in May that welcomes newcomers to Toronto, helps them understand and access a wide range of services, and celebrates their contributions to the city (City of Toronto, n.d.). The City's Newcomer Office plans the annual event and has been mentioned in an interview with the Community Development Officer at the Toronto Newcomer Office. The interviewee elaborated on how it is an example of Indigenous and newcomer collaboration, which will be further explained in the interview analysis section. The annual event features a number of activities, including a formal stage program, a citizenship ceremony for new Canadians, tours of City Hall, a newcomer marketplace, and an information fair. The Newcomer Day Celebrations are a direct action that relates to how cities manage diversity by supporting ethnic and cultural groups to maintain and celebrate their cultures (Burayidi, 2015).

\section{Indigenous-Newcomer Relations:}

\section{An Open Forum with Toronto's Immigrant Sector and Indigenous Partners}

On Thursday, February 20, 2020, the City's Newcomer Office hosted an open forum with Toronto's Immigrant Sector and Indigenous Partners to discuss Indigenous-Newcomer Relations (City of Toronto, n.d.). This specific initiative is responding to the TRC Calls to Action $93 \& 94$ on newcomers to Canada. The open forum's focus was on taking stock of existing and planned initiatives and educating newcomers and agency staff on Indigenous histories, cultures and perspectives, and it is particularly relevant for my MRP. The open forum also focused on mapping existing and planned partnerships between immigrant and refugee-serving agencies and Indigenous agencies; getting feedback and input 
from attendees on the "Vision for Toronto" plan; and the spirit of "nothing about us without us" including Indigenous communities, agencies and elders in co-creation and plan implementation, which will also be discussed further in the interview analysis section. Lastly, the open forum helped start the discussion on identifying a sector-wide collaborative approach to strengthening Indigenous-Newcomer relations and advancing reconciliation. The open forum is the first initiative to explicitly discuss Indigenous-newcomer relations in the City with Indigenous and immigration settlement organizations. This one-day event suggests that the City is in the early stages; however, immigrant organizations and Indigenous groups are interested in further exploring how the City can support and strengthen Indigenous-newcomer relations. The open forum will be the first initiative of many that will help bring community leaders together and will kick-start the process of more policy directions, initiatives, and positive impacts for Indigenous and non-Indigenous peoples.

Overall, the document scan helped identify current policy direction trends within the themes of advancing reconciliation and Indigenous-newcomer relations. The document scan also provided preliminary information on city-wide policy such as the Official Plan and geographic-specific policy such as the TOCore. Given the level of detail in the TOCore, the opportunities for more Indigenous-newcomer initiatives could happen in the downtown area of Toronto because of an emphasis on raising public awareness as indicated in the Statement of Commitment. An examination of the initiatives reveals some trends, including: Indigenous-newcomer relations initiatives are in the process of being implemented, and there is interest in doing more; however, this process is in very early stages. Additionally, Indigenous and newcomers are included in the discussions presented in these initiatives, but they are not mentioned together. The initiatives have indicated that there is a strong presence of Indigenous community organization leadership within the Aboriginal Affairs Committee and community partnerships.

The next section will discuss the semi-structured interview analysis and will showcase themes that relate to staff and divisional barriers, challenges, and opportunities to advancing reconciliation and supporting Indigenous-newcomer relations. The interviewees' responses will provide more details on and rationale for the process and decision-making process of those documents and initiatives.

\section{CHAPTER SIX: SEMI-STRUCTURED INTERVIEW ANALYSIS}

The document scan identified key trends in policy direction to understand how the city is responding to the Statement of Commitment and TRC Calls to Action. The initiative scan looked at implementation and action items of initiatives that can advance reconciliation and Indigenous-newcomer relations. The last qualitative data collection method involved semi-structured interviews with City staff 
in regard to their professional work and capacity in working for the City of Toronto. The semi-structured interviews lasted approximately 45 minutes to one hour and were conducted during the months of January and February 2020 at Toronto City Hall, with the exception of the written responses from Chief Planner 1 and Project Manager 1 in City Planning who chose to answer via email. The interviews were recorded and transcribed, and were then analyzed using selective coding using keywords (see Appendix C) to identify trends. The interviewees were guided with open-ended questions and an interview guide (See Appendix E). I conducted semi-structured interviews with City of Toronto staff $(n=7)$ from City Planning; Economic Development and Culture; the Newcomer Office; Parks, Forestry, and Recreation; and the Indigenous Affairs Office. The semi-structured interviews were an important data collection tool because they allowed City staff to provide reliable qualitative data that are not accessible by just scanning documents and initiatives on the City's website. Interviewing staff also provided an opportunity for further explanation and the rationale behind certain City actions, decision-making processes and history. They also helped in identifying challenges, barriers, and opportunities faced by staff who are working on policy or initiatives that relate to advancing reconciliation and supporting Indigenous-newcomer relations. The key trends are categorized into two themes: the TRC Calls to Action and Reconciliation and Indigenous-newcomer relations. These categories helped sort the different focuses of the trends.

\section{TRUTH \& RECONCILIATION COMMISSION CALLS TO ACTION \& RECONCILIATION THEMES}

\section{Theme 1: "Nothing About Us Without Us": Importance of the TRC and Indigenous-Led Leadership \& Relationship Building}

Throughout various discussions with City staff during the interviews, a common statement that often came up in conversation was "nothing about us without us". The statement implies that doing work with Indigenous peoples and communities is crucial. Relationship building and trust between nonIndigenous and Indigenous groups is highly important, especially for public servants who work for the city, as it is part of their duty to consult while going beyond tokenism and seeing them as stakeholders. As discussed by Director 2 in Economic Development and Culture, the duty to consult with Indigenous communities as public servants is important:

We [senior City staff] are also more broadly responsible as senior public servants working for the city. Our duty is to consult with the Indigenous community with a duty to keep them informed. We consult, as it relates to the legislation or any impacts, but there is an ongoing responsibility to keep talking, so we work through the City's formal channels. 
However, the challenges of working within a bureaucracy that are driven by project management timelines, which have specific goals, measurements, and outcomes, makes it difficult for City staff to sustain ongoing relationships within projects. As Consultant 1 from the Indigenous Affairs Office explained:

You know how project management starts with evaluation, but really for our communities we need consistency and ongoing partnerships and relationships. The way every institution is setup is that it is always project based or program based with that start, middle, and an end, and it shouldn't be that way. Relationships need to be harvested and supported for long periods of time. So it has been through these long-standing relationships, good work has come out.

For City staff to work on policies or initiatives, the engagement level of staff with Indigenous communities should be at the forefront before beginning any project and ensuring that it is an ongoing process that may take a long time. A common theme that stemmed from discussions was that several staff had many ideas for initiatives but did not know where to start. As a result, the creation of the Indigenous Affairs Office (IAO) has played a crucial role in divisions implementing and collaborating on policies and initiatives that advance the City's commitment to reconciliation and to support various staff to do this work. Establishing an Indigenous-led division that helps advise other divisions as well as advances Indigenous peoples and communities in the city was a crucial piece for the City of Toronto. As the Newcomer Office's Community Development Officer 1 said:

I think really what has been critical from the City of Toronto standpoint is once the Indigenous Affairs Office was formalized, it gave a lot of divisions an opportunity to work on the all of the things they have been thinking about to take shape because of the policy that is grounding a lot of this work. It's one of the things that we were waiting for to give power to our initiatives. We don't want to be separate, we wanted to have the backing of municipal policy to say that this is an important piece, and I think the fact that the work is still ongoing is even more amazing.

Municipal action and commitment to creating policies that ensure that the City is responding to the Calls to Action give staff the direction and accountability to fulfill the City's Statement of Commitment to Aboriginal communities in Toronto. The IAO has helped many staff on protocol and management work to ensure they are properly working with and for Indigenous communities. As discussed by Director 1, Indigenous leadership is an important aspect of working on projects, and as mentioned by Director 2 from Economic Development and Culture:

The IAO is an in-house advisory service, so there are a lot of people who didn't know where to get expert advice. You can go to them in a way that really wasn't possible before. Staff can get advice on protocol, on Indigenous-led initiatives already taking place, so it's great to not start from zero. We are doing a lot of comanagement work, and we seek advice on how to do that with the Indigenous community.

Another example of how the IAO has helped City staff with project advice is explained by the Economic Development and Culture's Senior Policy Advisor 1. The following quote explains how Senior Policy 
Advisor 1 was given direction from the IAO on how they should approach receiving information from the Indigenous community about the division's upcoming Indigenous engagement strategy:

We have a great relationship with the Indigenous Affairs Office. When we have questions, we meet with the office and run certain things past them. They are helpful with validation and gave suggestions. The feedback was that a facilitator should be someone with lived experiences and an Indigenous person, and that had not occurred to me, and so I thought that was positive feedback. I've asked them for lists of facilitators that they might have... The "nothing about us without us" came from them, which I really love that phrase.

Another main theme that came up was that the TRC Calls to Action and Statement of Commitment to Aboriginal Communities have legitimized the work of senior staff. As described by Senior Policy Advisor 1, the work of the TRC's Calls to Action and the Statement of Commitment have provided staff a starting point to initiate policy direction and implementation or actions by staff and divisions:

These documents [Statement of Commitment and TRC Calls to Action] give us something to piggyback on and give the work legitimacy. We can say we are doing this because of the Truth and Reconciliation Commission and the Inquiry into MMIWG ${ }^{16}$ and then the EDC divisional strategy includes four key areas such as inclusion and equity... and then the Equity Plan weaves in Indigenous peoples into the goals and strategies. Those strategies underpin and give weight to us doing this. We are using our equity plan, our divisional plan, the TRC to bolster why we are doing this.

The City of Toronto identifying priority Calls to Action that they will focus on and the Statement of Commitment have allowed staff such as Consultant 1 at the Indigenous Affairs Office to help lead direction and action by supporting staff who want to contribute to advancing reconciliation goals:

So now the TRC Calls to Action come out, and there is a lot more media attention, so now it seems like people are acting. I will also say that I think there is a little bit of a general mood in the City of Toronto and maybe Canada in general is that hopefully people are starting to learn and acknowledge and understand what happened to the First Peoples of Turtle Island because I do feel like people here who work in the City are trying to get it and are trying to act in what capacity they can. So it feels like there is good energy in the City right now, and we are at a good place where we can capitalize on that.

Since national discussions have occurred, governments have been tasked with addressing reconciliation.

As discussed by Director 2 from Economic Development and Culture, "the TRC had a huge impact on governments, including ours, and council has pushed us to do more work, and there hasn't been any push back from councillors or senior staff that have pushed back". Therefore, the TRC Calls to Action have had a huge impact on governments such as the City of Toronto to ensure that municipalities are doing more work that goes beyond tokenism. The national discussions are providing important starting points

\footnotetext{
${ }^{16}$ The National Inquiry into Missing and Murdered Indigenous Women and Girls' (MMIWG) Final Report reveals that persistent and deliberate human and Indigenous rights violations and abuses are the root cause behind Canada's staggering rates of violence against Indigenous women, girls and 2SLGBTQQIA people (National Inquiry into Missing and Murdered Indigenous Women and Girls, 2019).
} 
that divisions can further advance on to start thinking about ways of how their division or office can address issues. As discussed by Chief Planner 1 and Project Manager 1 in City Planning, the division is in the early phases of responding to the TRC Calls to Action:

We [City Planning] are answering the call (TRC Calls to Action \#79) to contribute, within this city, to a reconciliation framework for Canadian Heritage that integrates Indigenous history, heritage values and memory practices into our heritage planning and conservation practices. We are doing so, in particular, through an Indigenous Heritage Engagement Project, which is currently in an early co-development phase.

Overall, the theme of Indigenous-led leadership and the work of the Indigenous Affairs Office has been critical for staff to engage with on the TRC Calls to Action and to work on implementing policy or initiatives to help advance reconciliation. As reflected in the interviewees' quotes above, City staff have been engaging with the TRC Calls to Action and now have the support system and Indigenous leadership to do so.

\section{Theme 2: Going Beyond "Over-Consultation": Meaningful Engagement and Process}

As discussed in the document scan, community engagement strategies such as the Meeting in the Middle Indigenous Engagement Strategy are beginning to focus on primarily Indigenous communities. However, a common challenge that came up in interviews was that divisions and staff are having a difficult time with how to proceed with consultation and engage in a meaningful way. It was noted a few times that Indigenous communities in Toronto are "over-consulted" because of how many City divisions there are how the same Indigenous communities members show up. The challenge is then to address and create meaningful opportunities for people to collaborate rather than having surface-level discussions and meetings to meet an engagement requirement. As many divisions are trying to figure out how to do this, deciding on meaningful engagement practices is a work in progress. As Director 1 from Parks, Forestry and Recreation explains in regard to her project engagement strategies:

The ravine strategy was one we did recently which was just approved by council last week, and it has significant Indigenous interests in the ravine lands, so one of the things that the City has done and I've seen through both City Planning and Parks and Recreation, is how we do Indigenous engagement has really started to evolve, and I still think we are still in its first phase of really understanding how to make it work. I think part of the problem is that there is so many projects going on in the city, so the question becomes how do we engage in a way that is respectful of the time and effort of the various Indigenous populations?

Another common theme was that engagement needs to properly respect other groups' decision-making processes. Barry (2012) in Fawcett et al. (2015) discusses that long-term collaborative planning between Indigenous and non-Indigenous urban communities can create a better-balanced surface of power relations. Ensuring that there is flexibility and space for collaboration within a municipal setting is 
important. Ensuring that City policy supports collaboration and makes it easier would be an opportunity to further advance reconciliation and strengthen Indigenous-newcomer relations, especially within engagement. As described by Director 1 from Parks, Forestry, and Recreation:

I think engagement is all about clarity for any community. What is your project, clarity around what they can influence if they can't, and if you're not doing something, then it's really important to be clear about what you're asking them to influence, and then I think it's about understanding what your process is but also understanding what there process is and being respectful of that. And then I think the exciting part is about the synergy of ideas and collaboration, and I think, in part, we need to work more on our collaborative efforts on that to get some outcomes that we normally don't get. A good hallmark of engagement is that you have outcomes that you didn't expect at the initial meeting such as positive outcomes from initial ground.

As Fraser \& Viswanathan (2013) discuss, a cultural shift in how planning is done is needed. The actions described below talk about the cultural shift of approaching engagement and consultation in a different way. As described by Parks, Forestry, and Recreation Director 1, the City of Toronto acknowledges the challenge that Fraser \& Viswanathan (2013) identify and that the City will be creating a new Indigenous engagement strategy that will aim to effectively and meaningfully engage with Indigenous communities on their projects:

One of the things we've worked with the Indigenous Affairs Office on is the idea of doing a placemaking advisory circle, and to date what we have done is asked people and each team/project has asked Indigenous representatives if they want to participate, and you then realize when how many people and projects are asking the same people for engagement. So how do we create value out of it for them and we are basically piloting the idea of creating this placemaking advisory circle and to bring a number of projects there. And we are coordinating ourselves, and I think that, hopefully, the idea would be then to have the advisory circle meet as many times as they want to meet and then bring projects to them that they can have a meaningful focus on one project or if it's just an update or maybe two projects.

Additionally, working on co-creating through engagement can be a difficult task for City staff, and embracing the "messy" is important, as described by Senior Policy Advisor 1 from Economic Development and Culture:

[In order to] Co-create something [e.g. a community engagement strategy] you need to get input and consensus before. Those are interesting theoretical and practical implications in working with Indigenous peoples. I think it's good that we are struggling with this and we'll come out stronger with better processes. But right now, it's a little bit of a muddle. I would say we are not yet into the coherent stage, and I am not worried about it, but it is messy right now

Overall, City staff will have to create new methods and ways of engaging with Indigenous communities in order to avoid over-consultation. Also, there are initiatives that aim to re-shift how they engage with Indigenous communities by adjusting the City's engagement process. This trend suggests that cultural shifts are beginning to occur, especially for meaningful community engagement with Indigenous communities in Toronto, to produce better planning outcomes made by the City. 


\section{Theme 3: Learning and Competency Training: "People get it in a way that people haven't got ten years ago"}

Another common theme that surfaced during the interviews is that "City staff seem to get it" and conversations have matured in divisions and between staff, but much more needs to be done. As Brock (2009) discusses, diversity, training and cross-cultural communication initiatives create long-lasting changes in people's behaviour because they help shift mindsets and create a skillset, with people continuously wanting to learn more. This mindset shift supports Fawcett et al.'s (2015) argument that municipal culture needs to change to support co-existence and the co-production of spaces and places in cities. As discussed by Director 2 in Economic Development and Culture, there are staff who are ready and willing to do the work:

I think everybody gets that reconciliation is a significant priority, and there are enough individuals to spread across the organization who want to do something, and they are just ready to collaborate. The Indigenous Affairs Office has created the conditions to collaborate, so there is an affinity group of people who have been working on Indigenous issues who they can convene, and they are creating platforms for people to come together. That creates ancillary benefits for people to create tangible projects. For example, we are working on the George Street revitalization project, which is the City's single biggest effort in Indigenous place-making, from Dundas up to Gerrard.

Additionally, in the City of Toronto, there are approximately 35,000 full-time and part-time staff who work for the City, and this poses a challenge to ensure that all staff get the required training. However, senior management and staff aim to have a ripple effect by providing cultural competency training for all staff in their division and encourage staff to take additional training. As discussed by Chief Planner 1 and Project Manager 1 in City Planning, there is an effort being made by City Planning staff to get the training:

The City of Toronto offers Indigenous Cultural Competency training to all staff, and while not mandatory, there has been significant enrolment by City Planning staff. The City Planning training committee, along with the Chief Planner's Office, have ensured that all-staff meetings (AGM, PD Day, etc.) include opportunities for learning about Indigenous issues as they relate to our work as built environment professionals

Since there are outlets and opportunities for City staff to take additional training, the conversation around the importance of advancing reconciliation within the City has also matured and has created a culture of greater awareness of the history of Indigenous people. As described by Director 1 in Parks, Forestry, and Recreation, there has been greater awareness because of the TRC Calls to Action and the Statement of Commitment as discussed previously, "I just think there has been greater awareness in the city, whether if 
it's through the TRC or whether the fact that the City is good at engaging and recognizing where it has been weak and has taken on a priority to make it a better thing".

Overall, conversations and awareness of staff and their knowledge of the TRC Calls to Action have developed over time. As a result, City staff are capable and willing to work on projects that aim to advance reconciliation. Since the cultural competency training is not mandatory yet in all divisions, there will be an opportunity to make it mandatory and include Indigenous-newcomer relations components. In the TRC Calls to Action and Reconciliation section of the interviews, I discussed the importance of the nation-wide discussion and how the creation of the Indigenous Affairs Office helped strengthen and increase opportunities for City staff to engage in work related to advancing reconciliation. Indigenous-led management, support, and training for staff at the City of Toronto has initiated a starting point for staff to pursue their ideas in the development of new documents such as TOCore or the George Street Revitalization Project and initiatives such as the Toronto For All public education campaign and to further strengthen the potential impact of these documents and initiatives in Indigenous and nonIndigenous communities in the city.

\section{INDIGENOUS-NEWCOMER RELATIONS THEMES}

\section{Theme 4: "We haven't responded as we should be": More work still needs to be done}

As discussed in the document and initiative scan, the work of Indigenous-newcomer relations is in the very early stages; however, this is a sign of a cultural shift in immigration-focused divisions. Divisions such as the Newcomer Office and the Indigenous Affairs Office can further initiate this cultural shift by raising awareness of the significance and why other divisions should be involved. Fraser \& Viswanathan (2013) examine the role of municipal planning in relation to the duty to consult and conclude that municipal-First Nations engagement will require both legislative change and a cultural shift in how planning is done and what is included in the professional planning curriculum. As discussed by Community Development Officer 1 in the Newcomer Office, much work still needs to be done in providing immigrant-refugee sector organizations more information about the TRC Calls to Action and in making progress:

I think it has been more gradual, and to be honest I think that the TRC in certain communities across the country was a bit more of a prompt for some of the work to start. I have not felt that has not been the case in Toronto necessarily. I would say that within the immigrant-refugee serving sector/community, there unfortunately does not exist information about the TRC calls to action to begin with. I think that is the number one challenge because to have to respond to them you have to know about them. If you don't know about them, it's not quite clear what your roles or responsibilities or what your commitment should be to them. So, there is one place that we can do better, in terms of where the sector is concerned. But yeah, we haven't responded as we should be. 
As identified by the Economic Development and Culture's Senior Policy Advisor 1, projects and initiatives that relate to reconciliation and Indigenous-newcomer relations will have to take some time to communicate and develop in order to produce any policy direction or initiatives to implement in the future:

It's going to take a long time. I am not going to be surprised if it takes a year or two to really make it moving forward. It's about building relationships, and that's not easy, and there is quite frankly some distrust well-earned on the other side, so I think it will take years. And I think that's okay. We have to continue to push, but it's also important to be patient.

Another example identified by Senior Policy Advisor 1 from Economic Development and Culture was that the process of relationship building for City projects requires time and commitment:

Not everybody in the public service is comfortable with that uncertainty and pace, but I think it is what it is. I am more confident in what I know, and I just speak the truth, and when I get pushed about it, I just say "sorry, it's going to take longer", and that's one of the reasons in the inter-jurisdictional review that I emphasized that all the other case studies took two years to work on it and that it's just not something that you throw together. I mean, if you think about it, you don't build a relationship in two weeks, right? You need to continually demonstrate.

Even though City staff are in the early stages of pursuing Indigenous-newcomer initiatives, there are some ideas of where there are future opportunities in City Planning. As described by Chief Planner 1 and Project Manager 1 at City Planning, planning studies, the development of policies on affordable housing, and a city-wide Indigenous place-making framework are some ideas:

Future opportunities for creating and facilitating Indigenous-immigrant relations may include planning studies in neighbourhoods with significant immigrant populations (ex. Jane-Finch, which is in proximity to a significant archaeological site that consists of the remains of a Huron-Wendat village) or the development of policies around affordable housing, or the development of a city-wide Indigenous place making framework to guide the work of all City divisions (in the very, very early stages).

Overall, more work still needs to be done by the City to strengthen Indigenous-newcomer relations because it will take a long time to work with community members to identify the purpose and ultimate goals. To build meaningful relationships and trust between different community groups, it will take time. A barrier for Indigenous-newcomer relations to unfold is that project management requires deliverable outcomes, and, at this stage, staff do not know what the end goals would be.

\section{Theme 5: A Demographic Change \& Immigration Settlement Challenges}

Immigrants are often faced with structural challenges such as racism and discrimination or access to services and resources (Tuohy \& Talen, 2017). As a result, newcomer relationship building becomes less of a priority because there are more problems in settlement that immigrants experience such as 
finding affordable housing or access to transportation. As explained by Community Development Officer 1 from the Newcomer Office:

Both of these communities are the fastest growing in Canada, that it's only a matter of time that they take up space and would not have a choice but need to interact. And to be able to live in a cohesive and inclusive society, in a peaceful society, relationships need to be built. It has to happen. It's not for lack of interest on both sides; it's just not having opportunities to connect because when you look at the newcomer community, when they arrive in Toronto, they are faced by a number of challenges relating to their integration and settlement, and, often times, relationship building, specifically newcomer-relationship building, falls on the wayside of becoming a priority for several reasons. But it has to happen given the context that we live in. More than 52\% of Toronto's residents have a direct link of immigration as it is, so it is only a matter of time that immigration numbers are rising, and we have to start on focusing on building relationships between the two communities.

This suggests that the immigrant-refugee serving sector may not prioritize strengthening Indigenous-newcomer relations because there are more pressing issues that will determine their quality of life in Toronto. Additionally, as the Newcomer Office's Community Development Officer 1 stated:

I think the two communities [Indigenous \& newcomers] have a lot more in common than most people focus on. Often times, they both have been exposed to underemployment, poverty. A bulk of newcomers come from communities that have a colonial past in history. They have faced trauma and can relate on those things; they face different kinds of vulnerabilities and are marginalized on so many levels in our City alone, and I think that shared experience could help empower the two communities to have a lot of feedback and input into how the city that they live in should be and look like.

Therefore, it is important to recognize that Indigenous and newcomers have a lot in common in terms of lived experiences. To open dialogue and move towards policy change and action, it is important for municipal staff to focus their work on effectively co-integrating new immigrants and Indigenous peoples. To accomplish this, municipal staff need to explicitly support programming in cities that attract the most immigration (Brock, 2009). This is an opportunity for City Planning; Parks, Forestry and Recreation; and Economic Development and Culture to work together on Indigenous-newcomer relations through policy, programming, or creating spaces for dialogue. This would be a vital step towards creating an environment conducive to effective immigrant settlement and integration, including learning about the history and current context of Indigenous peoples and communities. The Newcomer Office and the Indigenous Affairs Office can further collaborate together to strengthen Indigenous-newcomer relations by supporting the divisions listed above. As discussed in the document and initiative scan, divisions often work in siloes with Indigenous communities and newcomer communities. This is an opportunity for greater cross-divisional collaboration to occur since Indigenous-newcomer relations are in the early stages. Through the conversations that come out of the discussions the Newcomer Office is having with 
their Indigenous-newcomer Open Forum, the Newcomer Office can help identify focus areas that divisions can respond to.

\section{Theme 6: Education First: Reducing Misinformation \& Negative Stereotypes}

Many staff members have discussed how in order to support Indigenous-newcomer relations, the City must first help educate on and communicate the history and stories of Indigenous peoples. As Reesor \& Bauder (2019) and Mathur et al. (2011) argued, the settlement of newcomers begins with learning about the land and who it belongs to, while acknowledging Indigenous displacement and genocide. Similar to case studies in Winnipeg, Manitoba, the attitudes of refugees and Aboriginals towards each other were negative or minimal because of the separation between the two groups (Madriaga-Vignudo, 2009). As described by Community Development Officer 1 from the Newcomer Office, the City has a responsibility to reduce misinformation through effective communication strategies:

Reducing misinformation, like recycling negative stereotypes because unfortunately newcomers have been known to do that. Due to no fault of theirs because the non-newcomer population and generally established Canadians sometimes hold those beliefs, but we have a duty and a responsibility to ensure that there is awareness in education and whether or not that comes in many forms.

To implement city-wide initiatives or policies, education was argued to be the first priority before implementing an Indigenous placemaking strategy. Additionally, as the Newcomer Office's Community Development Officer 1 explains:

That piece [Indigenous place-making] is important, but I feel like the educating piece needs to come first. Newcomers need to understand what the medicine wheel means next to the City of Toronto sign, to be able to have input and contribution to how things should be designed, with history being kept at the forefront of it.

There also has been a theme of a shift in how City Planning addresses the presence of Indigenous peoples in the city through land acknowledgements at community meetings. However, beginning with land acknowledgements should also be the only process in which City Planning engages newcomers with Indigenous history. As Toronto's City Planning Chief Planner 1 and Project Manager 1 said:

All community meetings hosted by City Planning are to begin with a land acknowledgement, using the language and guidance provided by the Indigenous Affairs Office, and including a personal reflection that relates one's own experience and/or work as a built environment professional. The Chief Planner has committed to providing further opportunities for building knowledge, understanding and competency of staff to undertake this small but important action toward reconciliation. To those present at community meetings, including Immigrants, the action of a Land Acknowledgement also increases the visibility of Indigenous people and their history and presence in the city. 
However, land acknowledgments during community meeting presentations may not be as effective because newcomers may not understand English as well or may not have the background information needed to understand the importance of a land acknowledgment. Additionally, educating newcomers through Indigenous learning opportunities in the built environment or through museums was also mentioned as a way to support Indigenous-newcomer relations. As described by Parks, Forestry, and Recreation's Director 1:

I think intercultural interaction is a given in a mature urban area, and so I think that we would want to be reflective and support that. I would say newcomers would have more appetite and interest in understanding what makes something special for Toronto, and if we reflect that Indigenous learning as part of it, it would just be part and parcel with what they understand to be important. So, if anything, they would be early adapters to all of that; it's not like they come in with preconceived notions that this was just their path and their community. They go in, and they see the restoration, some signage, they understand the history, and they go like "oh, this is interesting", so they don't come in with pre-piece, so in a way they can come in like a sponge and just absorb it.

Therefore, educating newcomers about Indigenous histories and cultures is important because they are willing to learn new information about Canada's history. Education strategies are a good starting place to reduce misinformation and stereotypes about Indigenous peoples and newcomers. The Toronto For All public education campaign, as discussed in the initiative scan, is a good opportunity to ensure that newcomers are educated from the proper sources that raise awareness of Indigenous people's history and diverse cultures. Overall, City divisions will have an important role to play in ensuring that Indigenous place-making can raise awareness of the Indigenous presence in the city.

\section{Theme 7: Celebration \& Recognition Through Arts \& Culture}

Throughout conversations, anecdotes of Indigenous and immigrant artists collaborating and producing art together was a common theme of celebration. Increasingly, in planning discourse and other literature about social change, the transformational role of stories and storytelling is explored, especially through community arts, undertaken with a community engagement approach, offering unique opportunities to create dialogue between groups (Brock, 2009). Storytelling and art could play an important role in fostering more discussions between Indigenous and newcomer groups. These activities

often happen in public spaces for both groups. Public art is a form of place-making that has been utilized by economic development and culture to ensure there are Indigenous components. As described by Economic Development and Culture's Director 1: 
Right now, we are working on something called the year of public art. It happens in 2021, and we are trying to figure out how we use it to advance reconciliation and how you signal that because we are at the front end of it. But we have a strategy framework for public art. In our language, we have included our commitments to advancing Indigenous reconciliation through place-making and public art and making it a foreground in everything that we do. We are trying to thread it through everything that we can in a very visible way.

In addition, a great example of how the celebration of arts and culture strengthens Indigenous-newcomer relations is described by the Newcomer Office's Community Development Officer 1:

Where things have progressed like nicely but not anything of our doing has been that, in the arts, we already see relationships forming between the two communities, and it is pretty obvious because the arts bring people together with different backgrounds. Last year, we attended an event hosted by the neighbourhoods arts network, part of the Toronto Arts Council Foundation, and it was an awards ceremony that was funded by RBC for newcomer artists, and at this event we met an Indigenous artist and a South Asian dancer who met through the program that they went through and decided to collaborate and create a unified Indigenous and newcomer dance.

Therefore, public art and celebrations of the arts and culture improve the potential of the City to support different ethnocultural groups to share their cultures and histories with each other. For example, as mentioned in the initiative scan, Newcomer Day celebrations would be an important initiative that focuses on how the City manages diversity while supporting cultures to be maintained and celebrated (Burayidi, 2015). Ensuring that City staff support Indigenous and newcomer artists' ability to participate is important. Additionally, as Economic Development and Culture's Director 1 explained:

The number of Indigenous artists who have been commissioned through the StreetArt initiative is great. An Indigenous artist is getting a big project for place-making to understand Indigenous presence, for example. All the councillors have been really helpful and want to collaborate.

Overall, public art and celebrations of arts and culture will be important to strengthening Indigenousnewcomer relations. Storytelling is an important way for Indigenous communities to tell their stories, and the same is true for many diverse newcomer communities in Toronto.

\section{Theme 8: The Importance of Implementing City-Wide Indigenous Place-making Efforts}

Learning about Indigenous history and culture should come first, and then spaces and learning opportunities should be created for Indigenous-newcomer groups to come together to help shape the city that they want to live in. Examples include plans, wayfinding projects, ravine systems, the waterfront, secondary plans, and projects such as the TOCore, George Street Revitalization Plan, and the Indian Residential Legacy Project in Nathan Phillips Square. As a way for this learning and education to occur, a city-wide Indigenous place-making effort would be an appropriate response to change and would 
represent identities and histories through the built environment and programming. As Matunga (2013) discusses, settler architecture and spaces dominate our cities, including colonial architecture, places of worship, parks, lots, and street patterns. However, the history of Indigenous peoples and other ethnocultural groups have not always been present throughout the city. For example, as the Indigenous Affairs Office's Consultant 1 describes:

All throughout the city, it is changing now, but only in the last few years, there is no acknowledgement of people who have lived here previously, and there is no recognition. As you get off the plane at Pearson, you have no idea you are on the territory of the Mississauga's New Credit, and there's no way for people visiting the city to know the history of the peoples here because we've been erased. So, everyone is doing a little bit of place-making in their portfolio because there are all these councilors trying to rename streets and places within their districts. So, supporting this is a big part of all of our jobs, which ties back to Indigenous learning.

Additionally, before Indigenous place-making can take place in Toronto, providing education and learning opportunities for newcomers is an important first step to moving forward. As described by the Newcomer Office's Community Development Officer 1:

Where things have progressed like nicely but not anything of our doing has been that in the arts we already see relationships forming between the two communities, and it's pretty obvious because the arts bring people together with different backgrounds.

In a city-wide Indigenous place-making framework, planning studies will be important tasks for planners to undo what Walker (2017) describes as structural violence. Further, planners should recognize and support Indigenous sovereignty and culture as well as produce equitable outcomes in the city for both Indigenous and newcomers. As described by Director 1 at Parks, Forestry and Recreation:

I think getting some outcomes, and we really have to look at that through a city-lens, even the connection to the Rouge National Park is really important because the Rouge is such a huge resource, and everything but it is in the federal piece, there's a whole bunch of things out there. But what are going to be impactful, what are going to be place-making opportunities that matter and that count, I think that's the harder question. I don't think having a policy that says, "thou shall engage with Indigenous communities". Well, that's great, everybody goes in and sends them letters, and they get a million letters, you know.

Additionally, as Tomiak (2017) discusses, settler states continue to pursue the transformation of Indigenous land into settler property and to govern Indigenous place-making and self-determination in cities. The leadership of Indigenous, community partners, the Indigenous Affairs Office, and the Aboriginal Affairs Committee have helped ensure that the City provides spaces and opportunities for the Indigenous community to determine Indigenous place-making initiatives. Therefore, it is important for municipalities and their staff to ensure that diverse ethnic and immigrant groups are also represented in 
the planning process of planning policy or initiative formulation. As this is a big step and requires time to build meaningful relationships, the City of Toronto is starting to co-develop an Indigenous Heritage Engagement project. As described by Chief Planner 1 and Project Manager 1 at City Planning:

The Planning Division is working in partnership with Museums and Heritage Services Unit (MHS) in the Economic Development and Culture Division, and with the Indigenous Affairs Office, to co-develop an Indigenous Heritage Engagement Project with Toronto's historic and contemporary Indigenous communities. While the objectives of this project are still being defined with Indigenous communities, the project will contribute to understanding the properties and areas within the City of Toronto that Indigenous peoples consider to have cultural heritage value or interest and to understanding Indigenous peoples' perspectives related to ethnographic and archaeological artefacts of Indigenous significance, which may be co-presented in the Museum of Toronto and MHS's existing museums.

City Planning and other divisions' initiatives are already taking place with a great focus on Indigenous people and history such as the TOCore, Indian Residential School Survivor Legacy Project in Nathan Phillips Square, and the George Street Revitalization Project, all of which are setting a precedent for more initiatives to continue because they provide opportunities to raise awareness of Indigenous presence, culture, and history. Non-Indigenous people, including newcomers in Toronto who are exposed to Indigenous place-making, will be able to learn, appreciate, and acknowledge Indigenous peoples. This process can ultimately lead to strengthening Indigenous-newcomer relations. There is still more work that needs to be done in order to establish a city-wide Indigenous place-making framework for all City Divisions, however, with current precedents, work responding to the Calls to Action and Statement of Commitment will help shift the culture and mindset of City staff and newcomers who learn through these projects.

Overall, the semi-structured interviews with City staff provided deeper context about how the City is currently engaging with the TRC Calls to Action and Indigenous-newcomer relations. Key themes from the interviews were categorized into TRC Calls to Action and reconciliation. The interviews helped further explore where the City is in terms of Indigenous-newcomer relations and identify that it is at the starting point. The interviewees also identified barriers and challenges, such as City administration and project management. The themes that fall under the TRC Calls to Action and reconciliation include the importance of Indigenous-led leadership and relationship building between City staff and Indigenous communities. Training and cultural competency training for City staff was another key theme for the TRC Calls to Action and reconciliation. The interviewees also mention that a lot of work still needs to be done and that the City needs to go beyond "over-consultation" with Indigenous communities. For Indigenousnewcomer relations topics, the demographic change represents challenges in the future of the City in terms of providing education and reducing misinformation. 


\section{CHAPTER SEVEN: CONCLUSION: PAST, PRESENT, AND FUTURE OF INDIGENOUS-NEWCOMER RELATIONS}

As Toronto's urban Indigenous and newcomer population is rapidly increasing, the City of Toronto is facing a new demographic reality. This MRP lays at the intersection of this demographic change, reconciliation, and the potential of city planning. The purpose of this MRP has been to explore how City staff are engaging (or not engaging) with the City's commitment to the TRC Calls to Action regarding Indigenous-newcomer relations in their practice. As part of my qualitative data collection and analysis, I conducted a document scan of City plans and policies, community engagement strategies, and divisional strategies. The purpose of the document scan was to explore the current level of policy direction taken by the City. My research also focused on completing an initiative scan of reports of action, Council member motions, and events to seek out the level of current engagement of the City with advancing reconciliation and Indigenous-newcomer relations. To supplement my findings in the document and initiative scan, I conducted semi-structured interviews with selected City staff and selectively coded the transcriptions to look for key trends that relate to Indigenous-newcomer relations. These data collection tools helped in seeking answers to the following research objectives.

\section{The City of Toronto and the TRC Calls to Action: Challenges and Barriers}

The MRP research revealed that the City has been responsive to the TRC Calls to Action and the City's Statement of Commitment, and is working towards advancing reconciliation through policy and initiatives. However, several barriers and challenges need to be addressed by the City in order to work towards strengthening Indigenous-newcomer relations, both through policies and through implementable actions and initiatives. A common trend identified through the data collection process concerns how engaging and working on projects with Indigenous and newcomer groups will require genuine commitment through meaningful community engagement. This was indicated as a challenge for staff because City projects often have deadlines, measures, and outcomes that need to be achieved. Another research finding concerns the differences between broader city-wide policy versus geography-specific planning policy documents in terms of how they focus on Indigenous communities, in particular, Indigenous place-making and reconciliation.

Divisional strategies also indicated that divisions are currently working in siloes with Indigenous communities and newcomer communities in Toronto, with no explicit Indigenous-immigrant relations focus until now. An important trend also indicates the prioritization of issues facing divisions when working with Indigenous and newcomer communities. Multiple issues are important and should take a higher priority. For example, the importance of Indigenous place-making and meaningful community 
engagement should take priority over Indigenous-newcomer relations. While several interviewees expressed interest in and concern for Indigenous-immigrant relations, they also pointed out that the City must first address city-wide issues facing the Indigenous and newcomer communities individually in order to provide them with essential services and addressing their needs (e.g. affordable housing, addressing barriers to education and training, inclusive local economies, quality of life). Before strengthening Indigenous-newcomer relations, the City must ensure that these communities are able to first have the support systems needed in place to participate in municipal planning. However, at the same time, municipal planning has an important role to play in future policy direction and action in regard to Indigenous-newcomer relations. The Open Forum on Indigenous-newcomer relations that took place in February 2020 and the current level of inter-divisional collaboration shows an interest in further exploring this in the near future.

\section{Opportunities for Indigenous-Newcomer Relations in the City of Toronto}

The analysis has shed light on how other policy priorities are currently taking precedence over Indigenous-newcomer relations in the City. Strengthening Indigenous-newcomer relations can be further explored through more conversations facilitated by the City with Indigenous community leaders and immigrant-refugee sector organizations to figure out what the key priorities in this regard. In terms of planning policy directions, there are opportunities for exploring how secondary plans and planning studies can further integrate Indigenous-newcomer relations through promoting Indigenous heritage and history in immigrant-majority neighbourhoods, for instance. Additionally, strengthening community engagement in different ways is an opportunity the city can capitalize on, working alongside the Newcomer Office and the Indigenous Affairs Office. Meaningful collaboration and engagement with Indigenous and newcomer communities in Toronto will be integral in defining what relationship building will look like for both communities.

As discussed previously, it will be important for the City of Toronto and the divisions examined in this MRP to first ensure that both communities are supported in their respective needs. Sandercock (2000) argues that a way of managing intercultural coexistence in shared space is through a 'therapeutic' dialogue approach that requires an open and communicative planning process, which involves negotiation and mediation in working through a problem with those directly affected. Therefore, for the process of reconciliation between Indigenous and newcomer groups, planners might be able to work within this framework of a 'therapeutic' planning to support Indigenous-newcomer relations through city planning

processes. Following Sandercock (2000), this 'therapeutic approach' would require planners to honor the life experiences of both communities, strengthening their communicative skills and, in multicultural or multi-ethnic contexts, facilitating spaces for cross-cultural understanding. 
Building meaningful relationships and trust in the ongoing process of reconciliation between Indigenous and newcomer groups is important in order to reduce negative stereotypes and increase knowledge and interaction. Therefore, Sandercock (2000) concludes that the work of planners in 'managing difference' is the work of negotiating fears and anxieties, mediating memories and hopes, and facilitating change and transformation between different cultural groups in our cities. In light of this, City planners in Toronto will have opportunities to integrate storytelling and the celebration of arts and culture in planning processes with Indigenous and newcomer communities, which is something this research has shown it is already beginning to happen. As discussed previously, City planning and related divisions are in the early stages of exploring opportunities in geography-specific planning studies with immigrant communities and Indigenous peoples. Key trends show that City Planning must continue to work in partnership with the Indigenous Affairs Office, the Newcomer Office, and other divisions to support Indigenous and newcomer communities. Then, ultimately, for planners to meaningfully engage in the process of reconciliation, they must continue to work in managing the differences within diversity in Toronto. 


\section{BIBLIOGRAPHY}

Bauder, H. (2011). Closing the immigration-Aboriginal parallax gap. Geoforum, 42(5), 517-519. Retrieved from: https://www.academia.edu/12770090/Closing the immigration_Aboriginal_parallax_gap

Bauder, H. (2019) "Connecting immigration to Canada's Indigenous past and present." Spotlight on Migration 2019/2. Retrieved from: https://www.ryerson.ca/content/dam/rcis/documents/RCIS_Spotlight_on_Migration_No_2 Conn ecting immigration to Canada's Indigenous past and present.pdf

Brock, S. (2009). Changing the Mind of the City: Preparing the Public Sector for a Multicultural Society. In Sandercock, L, Attili, G, Cavers, V, Carr, P (2009) Where Strangers Become Neighbours. Springer, DOI: https://doi.org/10.1007/978-1-4020-9035-6

Buraydi, M. A. and Wiles, A. (2015). Majority-Minority Cities: What Can they Teach Us and the Future of Planning Practice? In Cities and the politics of difference: Multiculturalism and diversity in urban planning University of Toronto Press.

Canadian Institute of Planners. (2019). Policy on Planning Practice and Reconciliation. Ottawa: Canadian Institute of Planners. Retrieved from: http://cip-icu.ca/getattachment/Topics-inPlanning/Indigenous-Planning/policy-indigenous-en-interactive.pdf. Aspx

City of Toronto. (2015). Official Plan. Retrieved from: https://www.toronto.ca/city-government/planningdevelopment/official-plan-guidelines/official-plan/

City of Toronto (2019). Quarterly Workforce Statistics - December 2019. Retrieved from: https://www.toronto.ca/city-government/data-research-maps/workforce-statistics/

City of Toronto (2018). Meeting in the Middle - Engagement Strategy and Action Plan. Retrieved from: https://www.toronto.ca/wp-content/uploads/2018/09/8eeb-SSHA-Meeting-in-the-Middle.pdf

City of Toronto (n.d.). City of Toronto Website: Parks, Forestry, and Recreation. Retrieved from: https://www.toronto.ca/city-government/accountability-operations-customer-service/cityadministration/staff-directory-divisions-and-customer-service/parks-forestry-recreation/

City of Toronto (n.d). City of Toronto Website: Toronto Newcomer Strategy. Retrieved from: https://www.toronto.ca/city-government/accountability-operations-customer-service/long-termvision-plans-and-strategies/toronto-newcomer-strategy/

City of Toronto (n.d). City of Toronto Website: Economic Development and Culture. Retrieved from: https://www.toronto.ca/city-government/accountability-operations-customer-service/cityadministration/staff-directory-divisions-and-customer-service/economic-development-culture/

City of Toronto (n.d). City of Toronto Website: City Planning. Retrieved from: https://www.toronto.ca/city-government/planning-development/

City of Toronto (n.d) City of Toronto Website: Indigenous Affairs Office. Retrieved from: https://www.toronto.ca/city-government/accessibility-human-rights/indigenous-affairs-office/

City of Toronto (2017). 2016 Census: Housing, Immigration and Ethnocultural Diversity, Aboriginal people. Retrieved from: https://www.toronto.ca/wp-content/uploads/2017/12/8ca4-5.-2016Census-Backgrounder-Immigration-Ethnicity-Housing-Aboriginal.pdf

City of Toronto (2015). Statement of Commitment to the Aboriginal Communities of Toronto - Annual Update 2015. Retrieved from: https:/www.toronto.ca/legdocs/mmis/2015/ex/bgrd/backgroundfile-85951.pdf

Cox, A. (2017). Settler Colonialism. obo in Literary and Critical Theory. Oxford University Press. Doi: 10.1093/obo/9780190221911-0029

De Costa, R., and Clark, T. (2011) Exploring non-Aboriginal Attitudes towards Reconciliation in Canada: The Beginnings of Targeted Focus Group Research in Cultivating Canada. In Cultivating Canada: reconciliation through the lens of cultural diversity. Mathur, Ashok, Dewar, Jonathan and DeGagné, Mike, eds. Aboriginal Healing Foundation Research Series . Aboriginal Healing Foundation, Ottawa, Ontario, pp. 327-339. 
Dean , J., Regier, K., \& Patel, A. (2018). Have You Met Our New Neighbours? Planning in the Age of Hyper-diversity. Retrieved from:

https://uwaterloo.ca/planning/sites/ca.planning/files/uploads/files/planning_in_the_age_of_hyper diversity_-_pragma_discussion_paper_2018.pdf

Fraser, C.M. \& Viswanathan, Leela. (2013). The crown duty to consult and ontario municipal-first nations relations: Lessons learned from the red hill valley parkway project. Canadian Journal of Urban Research. 22. 1-19.

Flyvbjerg, B., \& Richardson, T. (2002). Planning and Foucault: In Search of the Dark Side of Planning Theory. Lanning Futures: New Directions for Planning Theory, 44-62. Retrieved from https://ssrn.com/abstract=2278389

Galanakis, M. (2013). Intercultural Public Spaces in Multicultural Toronto. Canadian Journal of Urban Research, 22(1), 67-89. Retrieved from www.jstor.org/stable/26193926

Ghorayshi, P. (2010) Diversity and interculturalism: learning from Winnipeg's inner city, Conference on Urban Aboriginal Peoples, pp. ix-xxi. Toronto: Thompson Educational Publishing.

Government of Canada (2016). Canada Becomes a Full Supporter of the United Nations Declaration on the Rights of Indigenous Peoples. Retrieved from: https://www.canada.ca/en/indigenousnorthern-affairs/news/2016/05/canada-becomes-a-full-supporter-of-the-united-nationsdeclaration-on-the-rights-of-indigenous-peoples.html

Government of Canada (n.d.). Treaties and Agreements. Retrieved from: https://www.rcaanccirnac.gc.ca/eng/1100100028574/1529354437231\#chp2

Gyepi-Garbrah, J., Walker, R., \& Garcea, J. (2014). Indigeneity, Immigrant Newcomers and Interculturalism in Winnipeg, Canada. Urban Studies, 51(9), 1795-1811.

Hanson, E. (2009). Reserves. Indigenous Foundations: UBC. First Nations Studies Program. Retrieved from: https://indigenousfoundations.arts.ubc.ca/reserves/

Indigenous Corporate Training (2017). A Brief Definition of Decolonization and Indigenization. Retrieved from: https://www.ictinc.ca/blog/a-brief-definition-of-decolonization-andindigenization

Madriaga-Vignudo, L. (2009). “'More strangers than neighbours': Aboriginal-African refugee relations in Winnipeg's inner city." Unpublished paper. Winnipeg: The University of Winnipeg.

Mathur, A., Dewar, J., \& DeGagné Mike. (2011). Cultivating Canada: reconciliation through the lens of cultural diversity. Ottawa: Aboriginal Healing Foundation.

Mitra, S (2011) Learning Through Crossing Lines: An Intercultural Dialogue in Cultivating Canada. In Mathur, A., In Dewar, J., In DeGagné, M., \& Aboriginal Healing Foundation (Canada),. (2011). Cultivating Canada: Reconciliation through the lens of cultural diversity.Ottawa: Aboriginal Healing Foundation

McCartney, S., Herskovits, J., \& Hintelmann, L. (2018). Failure By Design: The On-Reserve First Nations' Housing Crisis And Its Roots In Canadian Evaluation Frameworks. The Canadian Journal of Native Studies, 38(2), 101-124.

McCartney, S. (2016, December 02). Re-Thinking Housing: From Physical Manifestation of Colonial Planning. Urban Planning, 20-31. doi:101.7645/up.v1i4.737

McLeod, Fraser*; Viswanathan, Leela; Macbeth, Janet; Whitelaw, Graham. 2017. Getting to Common Ground: A Comparison of Ontario, Canada's Provincial Policy Statement and the Auckland Council Regional Policy Statement with respect to Indigenous Peoples. Urban Planning, 2(1), $72-$ 87.

National Inquiry into Missing and Murdered Indigenous Women and Girls (2019). Reclaiming Power and Place: Final Report of the National Inquiry into Missing and Murdered Women and Girls. Retrieved from: https://www.mmiwg-ffada.ca/final-report/

Nejad, S. (2018). City Planning, Design, and Programming for Indigenous Urbanism and Ethnocultural Diversity in Winnipeg (Doctoral dissertation, University of Saskatchewan, Saskatoon, Canada). Retrieved from: http://hdl.handle.net/10388/8517 
Nejad, S., R. Walker, B. Macdougall, Y. Belanger, and D. Newhouse. (2019). “"This is an Indigenous City; Why Do not We See It?' Indigenous Urbanism and Spatial Production in Winnipeg." The Canadian Geographer 1-12. doi:10.1111/cag.12520.

Nejad, S.,walker, R., and Newhouse, D., (2019) Indigenous placemaking and the built environment: toward transformative urban design, Journal of Urban Design, DOI: $10.1080 / 13574809.2019 .1641072$

Phung, M (2011) Are people of colour settlers too? In Mathur, A., In Dewar, J., In DeGagné, M., \& Aboriginal Healing Foundation (Canada),. (2011). Cultivating Canada: Reconciliation through the lens of cultural diversity. Ottawa: Aboriginal Healing Foundation

Porter, Libby. (2013). Coexistence in cities: The challenge of Indigenous urban planning in the twentyfirst century. Reclaiming Indigenous Planning. 283-310.

Porter, L., and J. Barry. (2016). Planning for Coexistence? Recognizing Indigenous Rights through Land use Planning in Canada and Australia. New York: Routledge.

Reesor, R. and Bauder, H. (2019) "Building Relationships between Newcomers and Indigenous Peoples." In Bauder, H., ed. The Promise of Migration, p. 27-34

Rotondi MA, O'Campo P, O'Brien K, et al. (2017) Our Health Counts Toronto: using respondent-driven sampling to unmask census undercounts of an urban indigenous population in Toronto, Canada. BMJ Open 2017;7:e18936. https://doi:10.1136/bmjopen-2017-018936

Sandercock, L., Brock, S. (2009). Integrating an Immigrant Metropolis: Vancouvers Diversity Mission. In Sandercock, L, Attili, G, Cavers, V, Carr, P (2009) Where Strangers Become Neighbours. Springer, DOI: https://doi.org/10.1007/978-1-4020-9035-6

Sandercock, L., Brock, S. (2009). Inventing a Multicultural Nation: Canada's Evolving Story. In Sandercock, L, Attili, G, Cavers, V, Carr, P (2009) Where Strangers Become Neighbours. Springer, DOI: https://doi.org/10.1007/978-1-4020-9035-6

Sandercock, L. (2000). When strangers become neighbours: Managing cities of difference. Planning Theory \& Practice, 1(1), 13-30. doi:10.1080/14649350050135176

Smith, K.A. (2016). 'Professor explains the basics why we are all Treaty People'. Anishinabek News. Retrieved from: http://anishinabeknews.ca/2016/11/22/professor-explains-the-basics-why-we-areall-treaty-people/

Smith, L. T. (2012; 2013; 2016;). Decolonizing methodologies: Research and indigenous peoples (Second ed.). London: Zed Books.

Siemiatycki, M. (2011). Governing immigrant city: Immigrant political representation in Toronto. American Behavioral Scientist, 55(9), 1214-1234. doi:10.1177/0002764211407840

Statistics Canada. (2017a)., Dictionary, Census of Population, 2016. Accessed online October 10, 2019 at http://www12.statcan.gc.ca/census-recensement/2016/ref/dict/index-eng.cfm.

Statistics Canada. (2017b), Aboriginal Peoples Reference Guide, Census of Population, 2016. Accessed online October 10, 2019 at http://www12.statcan.gc.ca/censusrecensement/2016/ref/guides/009/98-500-x2016009-eng.cfm

Statistics Canada (2017c). Aboriginal peoples in Canada: Key results from the 2016 Census. Retrieved from: https://www150.statcan.gc.ca/n1/daily-quotidien/171025/dq171025a-eng.htm

O'Donnell, V., and LaPointe, R. (2019). Response mobility and the growth of the Aboriginal identity population, 2006-2011 and 2011-2016. Statistics Canada. Retrieved from: https://www150.statcan.gc.ca/n1/pub/99-011-x/99-011-x2019002-eng.pdf

Ontario Professional Planners Institute (2019). Indigenous Perspectives In Planning Report of the Indigenous Planning Perspectives Task Force Retrieved from: https://ontarioplanners.ca/inspiring-knowledge/indigenous-perspectives-in-the-planningprofession/introduction

Wong, B.M \& Fong, K. (2011). Vancouver Dialogues: First Nations, Urban Aboriginal and Immigrant Communities. Retrieved from: https://vancouver.ca/files/cov/dialogues-project-book.pdf

Tuohy \& Talen (2017). Urban Design in a New Age of Immigration. City \& Community 16:4 doi:10.1111/cico. 12268 
Truth and Reconciliation Commission of Canada. (2015). "Truth and Reconciliation Commission of Canada: Calls to Action." Retrieved from: https://nctr.ca/assets/reports/Calls to Action_English2.pdf

Teelucksingh, C. (2006). Claiming Space: Racialization in Canadian Cities. Waterloo: Wilfrid Laurier University Press. muse.jhu.edu/book/12255.

Yu, H (2011) Nurturing Dialogues between First Nations, Urban Aboriginal, and Immigrant Communities in Vancouver in Cultivating Canada In Mathur, A., In Dewar, J., In DeGagné, M., \& Aboriginal Healing Foundation (Canada),. (2011). Cultivating Canada: Reconciliation through the lens of cultural diversity.Ottawa: Aboriginal Healing Foundation 
Appendix A: Document Scan (Strategies and Plans)

\begin{tabular}{|c|c|c|c|}
\hline Document & Release Date & Description & City of Toronto Division \\
\hline $\begin{array}{l}\text { Meeting in the } \\
\text { Middle } \\
\text { Indigenous } \\
\text { Engagement } \\
\text { Strategy }\end{array}$ & $\begin{array}{l}\text { June } 2018 \\
\text { Post } \\
\text { Commitment } \\
\text { and Calls to } \\
\text { Action }\end{array}$ & $\begin{array}{l}\text { Meeting in the Middle - } \\
\text { Engagement Strategy and Action } \\
\text { Plan was co-created to foster better } \\
\text { relationships between the City of } \\
\text { Toronto Shelter Support and } \\
\text { Housing Administration (SSHA) } \\
\text { Division and Indigenous } \\
\text { organizations. Our vision is to } \\
\text { meaningfully address Indigenous } \\
\text { homelessness in Toronto by } \\
\text { addressing the City of Toronto's } \\
\text { Statement of Commitments to } \\
\text { Aboriginal Communities. }\end{array}$ & $\begin{array}{l}\text { Shelter Support and Housing } \\
\text { Administration (SSHA) Division and } \\
\text { Indigenous organizations }\end{array}$ \\
\hline Official Plan & $\begin{array}{l}\text { Consolidation } \\
\text { February } 2019\end{array}$ & $\begin{array}{l}\text { Intended to ensure that the City of } \\
\text { Toronto evolves, improves and } \\
\text { realizes its full potential in areas } \\
\text { such as transit, land use } \\
\text { development, and the } \\
\text { environment. February } 2019 \text { Office } \\
\text { Consolidation (Chapters 1-5 \& } \\
\text { Schedules 1-4) }\end{array}$ & City Planning \\
\hline $\begin{array}{l}\text { TOcore: } \\
\text { Downtown } \\
\text { Secondary Plan }\end{array}$ & June 5, 2019 & $\begin{array}{l}\text { TOcore was an initiative to prepare } \\
\text { a new plan for Toronto's } \\
\text { Downtown. In addition, a series of } \\
\text { five infrastructure-related strategies } \\
\text { have been developed to implement } \\
\text { the plan. These strategies cover } \\
\text { community facilities, parks and } \\
\text { public realm, mobility, energy and } \\
\text { water. The Downtown Plan is a } 25- \\
\text { year vision that sets the direction for } \\
\text { the city centre as the cultural, civic, } \\
\text { retail and economic heart of } \\
\text { Toronto and as a great place to live. }\end{array}$ & City Planning \\
\hline $\begin{array}{l}\text { Toronto } \\
\text { Newcomer } \\
\text { Strategy Plan }\end{array}$ & $\begin{array}{l}\text { Approved in } \\
2013\end{array}$ & $\begin{array}{l}\text { Toronto is one of the most } \\
\text { multicultural urban areas in the } \\
\text { world. Each year tens of thousands } \\
\text { of people from around the globe } \\
\text { choose our city as their new home. } \\
\text { Their diverse cultures and } \\
\text { communities have helped create } \\
\text { Toronto's identity as a vibrant }\end{array}$ & Toronto Newcomer Office \\
\hline
\end{tabular}




\begin{tabular}{|c|c|c|c|}
\hline & & $\begin{array}{l}\text { global city. The Toronto Newcomer } \\
\text { Strategy is designed to } \\
\text { improve newcomer settlement } \\
\text { through shared leadership, stronger } \\
\text { collaboration and a more seamless } \\
\text { and well-coordinated service } \\
\text { system. } \\
\text { The strategy is funded by } \\
\text { Immigrant, Refugee and Citizenship } \\
\text { Canada (IRCC) as part of the Local } \\
\text { Immigration Partnership initiative. }\end{array}$ & \\
\hline $\begin{array}{l}\text { Statement of } \\
\text { Commitment to } \\
\text { the Aboriginal } \\
\text { Communities of } \\
\text { Toronto }\end{array}$ & July 2010 & $\begin{array}{l}\text { The City of Toronto's commitment } \\
\text { to Indigenous people of Toronto } \\
\text { based on priority Calls to Action on } \\
\text { the path to Reconciliaiton }\end{array}$ & All \\
\hline $\begin{array}{l}\text { George Street } \\
\text { Revitalization - } \\
\text { Streetscaping } \\
\text { Plan }\end{array}$ & May 18, 2018 & $\begin{array}{l}\text { Council-approved project, George } \\
\text { Street Revitalization will see the } \\
\text { reinvention of the northernmost } \\
\text { block of George Street and } \\
\text { transformation of Seaton House } \\
\text { men's shelter into a world-class } \\
\text { facility providing specialized care } \\
\text { for vulnerable populations. }\end{array}$ & City Planning \\
\hline $\begin{array}{l}\text { Toronto } \\
\text { Newcomer } \\
\text { Strategy - } \\
\text { Progress } \\
\text { Report }\end{array}$ & 2016 & $\begin{array}{l}\text { Over the past ten years, more than } \\
\text { six hundred thousand new } \\
\text { permanent residents have arrived in } \\
\text { Toronto. Recognizing the critical } \\
\text { importance of the successful } \\
\text { settlement and integration of } \\
\text { newcomers, City Council approved } \\
\text { the Toronto Newcomer Strategy } \\
\text { (TNS) in } 2013 \text { and adopted the } \\
\text { Integrating Cities Charter in } 2014 \text {. } \\
\text { Over the past three years, the } \\
\text { Toronto Newcomer Office (TNO) } \\
\text { has been working with multiple City } \\
\text { divisions and partners to coordinate } \\
\text { the implementation of the Strategy } \\
\text { and Charter, and integrate } \\
\text { newcomer needs into strategic } \\
\text { planning, policy development and } \\
\text { service improvements. Significant } \\
\text { advancements have been made, }\end{array}$ & Newcomer Office \\
\hline
\end{tabular}




\begin{tabular}{|c|c|c|c|}
\hline & & $\begin{array}{l}\text { firmly establishing City of Toronto } \\
\text { as a critical stakeholder and leader } \\
\text { in the settlement and integration of } \\
\text { newcomers and refugees. This } \\
\text { report provides an update on the } \\
\text { progress related to the } \\
\text { implementation of the Toronto } \\
\text { Newcomer Strategy since } 2014 \text {, } \\
\text { including the City of Toronto } \\
\text { Refugee Resettlement Program. It } \\
\text { also seeks authority to extend the } \\
\text { programming for the Refugee } \\
\text { Resettlement Program into } 2017 .\end{array}$ & \\
\hline $\begin{array}{l}\text { Implementation } \\
\text { Guidelines for } \\
\text { Section } 37 \text { of } \\
\text { the Planning } \\
\text { Act }\end{array}$ & $\begin{array}{l}\text { Consolidated } \\
\text { amendments } \\
\text { January } 2016\end{array}$ & $\begin{array}{l}\text { The Section } 37 \text { Implementation } \\
\text { Guidelines were adopted by City } \\
\text { Council on November 20, } 2007 \text { and } \\
\text { have been revised to consolidate } \\
\text { Council adopted amendments up to } \\
\text { July 2013. The Guidelines are } \\
\text { intended to assist in the } \\
\text { implementation of the Section } 37 \\
\text { policies of the Official Plan (section } \\
\text { 5.1.1). The guidelines are designed } \\
\text { to be read in conjunction with the } \\
\text { Official Plan policies, and address } \\
\text { implementation principles, other } \\
\text { implementation issues, and } \\
\text { guidelines for securing specific } \\
\text { types of community benefits. }\end{array}$ & City Planning \\
\hline
\end{tabular}


Appendix B: Initiative Scan (Action Plans, Events, and Working Groups)

\begin{tabular}{|c|c|c|c|}
\hline Initiative & $\begin{array}{l}\text { Date/ } \\
\text { Timeframe }\end{array}$ & Description & Division \\
\hline $\begin{array}{l}\text { Indigenous- } \\
\text { Newcomer } \\
\text { Relations: An } \\
\text { Open Forum with } \\
\text { Toronto's } \\
\text { Immigrant Sector } \\
\text { and Indigenous } \\
\text { Partners }\end{array}$ & $\begin{array}{l}\text { February } \\
2020\end{array}$ & $\begin{array}{l}\text { The City of Toronto's Newcomer } \\
\text { Office (TNO), in partnership with } \\
\text { the City's Indigenous Affairs Office } \\
\text { and OCASI - Ontario Council of } \\
\text { Agencies Serving Immigrants are } \\
\text { inviting you to an open forum to } \\
\text { explore the role that the immigrant } \\
\text { and refugee-serving sector plays in } \\
\text { advancing reconciliation. } \\
\text { Immigrant and refugee-serving } \\
\text { sector agencies, Indigenous } \\
\text { agencies, and researchers are } \\
\text { invited to help us: } \\
\text {-Take stock of initiatives that } \\
\text { foster understanding between } \\
\text { newcomer and Indigenous } \\
\text { communities } \\
\text { _Map existing partnerships } \\
\text { between immigrant and refugee } \\
\text { serving agencies, and Indigenous } \\
\text { agencies } \\
\text { Identify a sector-wide } \\
\text { collaborative approach to } \\
\text { strengthening Indigenous- } \\
\text { newcomer relations, and } \\
\text { _Provide feedback on the } \\
\text { proposed initiative to strengthen }\end{array}$ & $\begin{array}{l}\text { City of Toronto's Newcomer Office, } \\
\text { City's Indigenous Affairs Office, and } \\
\text { external community partner: OCASI - } \\
\text { Ontario Council of Agencies Serving } \\
\text { Immigrants }\end{array}$ \\
\hline $\begin{array}{l}\text { Indian Residential } \\
\text { School Survivor } \\
\text { (IRSS) Legacy } \\
\text { project }\end{array}$ & $\begin{array}{l}\text { June } 17, \\
2018\end{array}$ & $\begin{array}{l}\text { In } 2017 \text {, the City was approached } \\
\text { by Toronto Council Fire (TCF) to } \\
\text { partner in the installation of a large } \\
\text { structure at Nathan Phillips Square } \\
\text { (NPS) to recognize the experience } \\
\text { of Indian residential school } \\
\text { survivors, in fulfilment of Call to } \\
\text { Action } 82 \text {. On November 7, 2017, } \\
\text { Council adopted a motion directing } \\
\text { the General Manager, Economic } \\
\text { Development and Culture (EDC) } \\
\text { and the Deputy City Manager, } \\
\text { Internal Corporate Services, to } \\
\text { work with TCF to determine the } \\
\text { feasibility of the project and report } \\
\text { back to Council in the first quarter }\end{array}$ & $\begin{array}{l}\text { City Planning, Economic Development } \\
\text { and Culture, Indigenous Affairs Office }\end{array}$ \\
\hline
\end{tabular}




\begin{tabular}{|c|c|c|c|}
\hline & & $\begin{array}{l}\text { of } 2018 . \text { An initial update was } \\
\text { provided to the Government } \\
\text { Management Committee on April } \\
3,2018 \text {. Planning has accelerated } \\
\text { since that time. This report provides } \\
\text { a further update on the state of } \\
\text { design, engineering, budget, } \\
\text { programming and stakeholder } \\
\text { engagement as of June } 2018 \text {. While } \\
\text { some risks to the project remain, } \\
\text { and are detailed below, the project } \\
\text { is considered generally feasible. }\end{array}$ & \\
\hline Toronto for All & & $\begin{array}{l}\text { Public Education to Support Civic } \\
\text { Resiliency } \\
\text { The initiative is a municipal tool } \\
\text { that supports the civic resiliency for } \\
\text { all Toronto residents. Civic } \\
\text { resiliency is the capacity of a group } \\
\text { of residents or community to adapt } \\
\text { to the evolving complexity and } \\
\text { diversity of their social } \\
\text { environment by building good } \\
\text { relationships and viewing these } \\
\text { changes as a strength. Civic } \\
\text { resiliency can be measured in } \\
\text { residents' awareness of - and } \\
\text { engagement with - the systemic } \\
\text { barriers that exist for people in their } \\
\text { environment due to group } \\
\text { membership. Implicit biases, } \\
\text { negative attitudes, stereotypes and } \\
\text { prejudices negatively impact our } \\
\text { civic resiliency. }\end{array}$ & $\begin{array}{l}\text { Equity, Diversity, and Human Rights } \\
\text { and Social Development, Finance and } \\
\text { Administration }\end{array}$ \\
\hline $\begin{array}{l}\text { Aboriginal Affairs } \\
\text { Committee Terms } \\
\text { of Reference }\end{array}$ & 2015 & $\begin{array}{l}\text { City Council at its meeting on February } \\
10,2015 \text { approved the Terms of } \\
\text { Reference for the Aboriginal Affairs } \\
\text { Committee. }\end{array}$ & City Manager \\
\hline $\begin{array}{l}\text { Indigenous Centre } \\
\text { for } \\
\text { Entrepreneurship } \\
\text { and Innovation - } \\
\text { Member Motion }\end{array}$ & $\begin{array}{l}\text { July } 23 \text {, } \\
2018\end{array}$ & $\begin{array}{l}\text { Authorize approval to accept } \\
\text { federal funding for the Indigenous } \\
\text { Centre for Innovation and } \\
\text { Entrepreneurship - by Councillor } \\
\text { Kristyn WongTam, seconded by } \\
\text { Councillor Mike Layton }\end{array}$ & Indigenous Affairs office \\
\hline $\begin{array}{l}\text { Incorporating } \\
\text { Indigenous Place- }\end{array}$ & $\begin{array}{l}\text { November } \\
3,2017\end{array}$ & $\begin{array}{l}\text { Presentation from the Project } \\
\text { Manager, Strategic Initiatives, City }\end{array}$ & $\begin{array}{l}\text { Parks, Forestry and Recreation and } \\
\text { City Planning }\end{array}$ \\
\hline
\end{tabular}




\begin{tabular}{|l|l|l|l|}
\hline $\begin{array}{l}\text { Making in the city } \\
\text { of Toronto's Parks } \\
\text { Capital Projects } \\
\text { Presentation }\end{array}$ & & $\begin{array}{l}\text { Planning, the Manager, Public } \\
\text { Relations, Parks, Forestry and } \\
\text { Recreation, and the Director, Policy } \\
\text { and Strategic Planning, Parks, } \\
\text { Forestry and Recreation, on Our } \\
\text { Common Grounds: Incorporating } \\
\text { Indigenous Place-Making in } \\
\text { Toronto's Parks and Public Realm }\end{array}$ & \\
\hline $\begin{array}{l}\text { Fulfilling Calls to } \\
\text { Action from Truth } \\
\text { and Reconciliation } \\
\text { Commission } \\
\text { Report }\end{array}$ & 2016 & $\begin{array}{l}\text { April 1, } \\
\text { progress made by the City, in } \\
\text { partnership with the } \\
\text { Aboriginal Affairs Advisory } \\
\text { Committee, in implementing } \\
\text { the relevant eight Calls to } \\
\text { Action. }\end{array}$ & ALL \\
\hline
\end{tabular}


Appendix C: Thematic Coding Keywords

\begin{tabular}{|l|}
\hline Keywords \\
\hline Indigenous \\
\hline Aboriginal \\
\hline First Nation, Inuit, Metis \\
\hline Multiculturalism/Multicultural \\
\hline Equity, Diversity, and Inclusion \\
\hline Newcomer \\
\hline Immigration/Immigrant \\
\hline Reconciliation \\
\hline $\begin{array}{l}\text { Truth and Reconciliation } \\
\text { Commission/TRC }\end{array}$ \\
\hline Equity-seeking groups \\
\hline Vulnerable populations \\
\hline Social Equity \\
\hline
\end{tabular}




\section{Appendix D: Interviewee List and Divisions}

\begin{tabular}{|l|l|}
\hline Staff & Division \\
\hline Chief Planner and Executive Director 1 & City Planning \\
\hline Project Manager 1, Archaeology & City Planning \\
\hline $\begin{array}{l}\text { Director 1, Parks Development and Capital Projects } \\
\text { \& Interim Director of Policy and Strategic Planning } \\
\text { Group }\end{array}$ & Parks, Forestry, and Recreation \\
\hline Director 2, Arts \& Culture Services & \\
\hline Senior Policy Advisor 1 & Economic Development and Culture \\
\hline Consultant 1 & Economic Development and Culture \\
\hline Community Development Officer 1 & Indigenous Affairs Office \\
\hline
\end{tabular}


Appendix E: Interview Guide with Questions

\section{Updated Jan 14}

\section{Major Research Project Topic: Exploring Indigenous-Immigrant Relations in Toronto: Municipal Planning and a Pathway to Reconciliation}

Research Question: How are municipal planners and staff are engaging (or not engaging), with the City's commitment to the TRC's calls to action regarding Indigenous-immigrant relations in their practice?

Purpose: Expert interviews to ask diverse city officials about their professional work and capacity working for the City of Toronto. Important to remind staff that they are being asked to provide their professional opinions as representatives of their employers.

Interview Length: 40 min-1hr (during the month of January 2020)

\section{List of Interviewees (Max 10):}

1. Chief Planner \& Executive Director | City Planning

2. Archaeology Project Manager | City Planning

3. Consultant of Indigenous Affairs Office | City Manager's Offices

4. Director, Parks Development and Capital Projects $\mid$ Parks, Forestry, and Recreation (PF\&R)

5. Director, Arts and Culture Services | Economic Development and Culture

6. Community Development Officer, Newcomer Office | Social Development, Finance, and Administration

*Open to snowballing effect of staff/departments I may reach out to*

\section{Research Objectives:}

- To gain a better understanding of how city planning can facilitate intercultural community planning between Indigenous and immigrant communities;

- to identify issues/challenges faced by municipal staff engaging with reconciliation and Indigenous-immigrant relations;

- and to understand any municipal barriers or challenges with resources and community buy-in for reconciliation focused initiatives

\section{Semi-Structured Questions (4-5 questions)}

- Please describe your role and duties as ?

- What are some projects or initiatives that you are working on right now?

- How is reconciliation considered in your work projects?

- Is your department/unit currently doing work on Indigenous-immigrant relations?

- What are some opportunities or weaknesses in policy or initiatives that can benefit from the Truth and Reconciliation calls to action in regard to Indigenous-immigrant experience in Toronto?

- How can intercultural relations such as Indigenous-immigrant relations inform your department's strategic initiatives and/or vision within the context of truth and reconciliation? 